Cochrane Database of Systematic Reviews

\title{
Surgical interventions for age-related cataract (Review)
}

Riaz Y, Mehta JS, Wormald R, Evans JR, Foster A, Ravilla T, Snellingen T

Riaz Y, Mehta JS, Wormald R, Evans JR, Foster A, Ravilla T, Snellingen T.

Surgical interventions for age-related cataract.

Cochrane Database of Systematic Reviews 2006, Issue 4. Art. No.: CD001323.

DOI: 10.1002/14651858.CD001323.pub2.

www.cochranelibrary.com 
TABLE OF CONTENTS

HEADER 1

ABSTRACT

PLAIN LANGUAGE SUMMARY

BACKGROUND

OBJECTIVES

METHODS

RESULTS

DISCUSSION

AUTHORS' CONCLUSIONS

ACKNOWLEDGEMENTS

REFERENCES

CHARACTERISTICS OF STUDIES

DATA AND ANALYSES

Analysis 1.1. Comparison 1 PHACOEMULSIFICATION WITH PCIOL VERSUS EXTRACAPSULAR EXTRACTION WITH PCIOL, OutCome 1 Clinical complications.

Analysis 1.2. Comparison 1 PHACOEMULSIFICATION WITH PCIOL VERSUS EXTRACAPSULAR EXTRACTION WITH PCIOL, OutCome 2 Complications during surgery.

Analysis 2.1. Comparison 2 PHACOEMULSIFICATION WITH PCIOL VERSUS MANUAL SMALL INCISION EXTRACTION WITH PCIOL, Outcome 1 Best corrected vision worse than 6/60, 4-12 weeks after surgery.

Analysis 2.2. Comparison 2 PHACOEMULSIFICATION WITH PCIOL VERSUS MANUAL SMALL INCISION EXTRACTION WITH PCIOL, Outcome 2 Functional vision worse than 6/18, 4-12 weeks after surgery.

Analysis 2.3. Comparison 2 PHACOEMULSIFICATION WITH PCIOL VERSUS MANUAL SMALL INCISION EXTRACTION WITH PCIOL, Outcome 3 Complications during surgery.

Analysis 3.1. Comparison 3 EXTRACAPSULAR EXTRACTION WITH PCIOL VERSUS MANUAL SMALL INCISION EXTRACTION WITH PCIOL, Outcome 1 Best corrected vision worse than 6/60, 4-12 weeks after surgery.

Analysis 3.2. Comparison 3 EXTRACAPSULAR EXTRACTION WITH PCIOL VERSUS MANUAL SMALL INCISION EXTRACTION WITH PCIOL, Outcome 2 Functional vision worse than 6/18, 4-12 weeks after surgery.

Analysis 3.3. Comparison 3 EXTRACAPSULAR EXTRACTION WITH PCIOL VERSUS MANUAL SMALL INCISION EXTRACTION WITH PCIOL, Outcome 3 Complications during surgery.

Analysis 4.1. Comparison 4 INTRACAPSULAR EXTRACTION WITH ACIOL VERSUS INTRACAPSULAR EXTRACTION WITH GLASSES, Outcome 1 Best-corrected vision worse than 6/60, one year after surgery.

Analysis 4.2. Comparison 4 INTRACAPSULAR EXTRACTION WITH ACIOL VERSUS INTRACAPSULAR EXTRACTION WITH GLASSES, Outcome 2 Functional vision worse than $6 / 18$, one year after surgery.

Analysis 4.3. Comparison 4 INTRACAPSULAR EXTRACTION WITH ACIOL VERSUS INTRACAPSULAR EXTRACTION WITH GLASSES,

Outcome 3 Clinical complications.

ADDITIONAL TABLES

APPENDICES

WHAT'S NEW

HISTORY

CONTRIBUTIONS OF AUTHORS

DECLARATIONS OF INTEREST

INDEX TERMS 
[Intervention Review]

\section{Surgical interventions for age-related cataract}

Yasmin Riaz ${ }^{1}$, Jod S Mehta², Richard Wormald³, Jennifer R Evans ${ }^{3}$, Allen Foster ${ }^{4}$, Thulasiraj Ravilla ${ }^{5}$, Torkel Snellingen 6

${ }^{1}$ Moorfields Eye Hospital, London, UK. ${ }^{2}$ C/o Prof D Tan, Singapore National Eye Centre, Singapore, Singapore. ${ }^{3}$ Cochrane Eyes and Vision Group, ICEH, London School of Hygiene \& Tropical Medicine, London, UK. " Department of Infectious and Tropical Diseases, London School of Hygiene and Tropical Medicine, London, UK. ${ }^{5}$ Aravind Eye Hospital, Madurai, India. ${ }^{6}$ Centre for International Health, Forskningsparken Breivilka, Tromsø, Norway

Contact address: Yasmin Riaz, Moorfields Eye Hospital, City Road, London, EC1V 2PD, UK. yasmin.riaz@gmail.com.

Editorial group: Cochrane Eyes and Vision Group.

Publication status and date: Edited (no change to conclusions), published in Issue 1, 2009.

Citation: Riaz Y, Mehta JS, Wormald R, Evans JR, Foster A, Ravilla T, Snellingen T. Surgical interventions for age-related cataract. Cochrane Database of Systematic Reviews 2006, Issue 4. Art. No.: CD001323. DOI: 10.1002/14651858.CD001323.pub2.

Copyright @ 2009 The Cochrane Collaboration. Published by John Wiley \& Sons, Ltd.

\section{A B S T R A C T}

\section{Background}

Cataract accounts for $50 \%$ of blindness globally and remains the leading cause of visual impairment in all regions of the world, despite improvements in surgical outcomes (WHO 2005). This number is expected to rise due to an aging population and increase in life expectancy. Although cataracts are not preventable, their surgical treatment is one of the most cost-effective interventions in healthcare.

\section{Objectives}

To compare the effects of different surgical interventions for age-related cataract.

\section{Search methods}

We searched CENTRAL, MEDLINE, EMBASE up to July 2006, NRR Issue 32005 , the reference lists of identified trials and we contacted investigators and experts in the field for details of published and unpublished trials.

\section{Selection criteria}

We included randomised controlled trials (RCTS).

\section{Data collection and analysis}

Two review authors independently extracted data and discrepancies were resolved by discussion. Where appropriate, risk ratios, odds ratios and weighted mean differences were summarised after assessing heterogeneity between the studies.

\section{Main results}

We identified 17 trials that randomised a total of 9627 people. Phacoemulsification gave a better visual outcome than extracapsular surgery but similar average cost per procedure in Europe but not in poorer countries. Extracapsular surgery with posterior chamber lens implant and ICCE with or without an anterior chamber intraocular lens (IOL) implant gave acceptable visual outcomes but extracapsular surgery had less complications. Manual small incision surgery provides better visual outcome than ECCE but slightly inferior unaided visual acuity compared to phacoemulsification.

\section{Authors' conclusions}

This review provides evidence from seven RCTs that phacoemulsification gives a better outcome than ECCE with sutures. We also found evidence that ECCE with a posterior chamber lens implant provides better visual outcome than ICCE with aphakic glasses. The long term effect of posterior capsular opacification (PCO) needs to be assessed in larger populations. The data also suggests that ICCE with an anterior 
chamber lens implant is an effective alternative to ICCE with aphakic glasses, with similar safety. Phacoemulsification provides the best visual outcomes but will only be accessible to the poorer countries if the cost of phacoemulsification and foldable IOLs decrease. Manual small incision cataract surgery provides early visual rehabilitation and comparable visual outcome to PHACO. It has better visual outcomes than ECCE and can be used in any clinic that is currently carrying out ECCE with IOL. Further research from developing regions are needed to compare the cost and longer term outcomes of these procedures e.g. PCO and corneal endothelial cell damage.

\section{PLAIN LANGUAGE SUMMARY}

\section{Surgical treatment for cataract caused by aging changes in the lens which reduce its transparency and leads to visual impairment}

Cataract is a major cause of global blindness, accounting for $50 \%$ to $80 \%$ in developing countries. The number of people blind from cataract is expected to rise due to the increase in life expectancy. Aging causes changes in the lens protein leading to opacification of the lens. These changes are often bilateral although maybe asymmetric. Symptoms from cataracts include glare, blurred vision, progressive decrease in visual function and blindness. Surgery is currently the only treatment option once the lens has opacified and vision is decreasing. The indication for surgery is based on whether the patient's reduced visual function interferes with their quality of life. Different surgical techniques have been developed to remove the cloudy lens which is replaced either by an intraocular lens (positioned in the posterior chamber or the anterior chamber of the eye), aphakic glasses or contact lens. There are four main forms of cataract extraction surgery: intracapsular (ICCE), extracapsular (ECCE), phacoemulsification (PHACO) and manual small incision (MSICS). The review authors searched the medical literature and identified 17 randomised controlled trials (9627 participants) investigating the different surgical interventions. Six of these trials suggested that PHACO gives a better outcome than ECCE. They suggest a better uncorrected visual acuity (UCVA) following PHACO than ECCE but the majority of the trials showed no difference in best corrected visual acuity (BCVA) between the two groups. The costs per procedure were not markedly different between the two techniques in a UK based study, however, a Malaysian study showed ECCE to be significantly cheaper. A study comparing MSICS and ECCE, advocated MSICS as the procedure of choice due to equal costs and better visual results. Two studies compared the results of PHACO and MSICS. Phacoemulsification having a significantly higher proportion of patients with UCVA $>6 / 18(81.1 \%$ versus $71 \%)$ but there was no difference in BSCVA. Trials comparing costs of PHACO and MSICS are important for future research. Manual small incision surgery offers an alternative technique in developing countries as it provides acceptable visual outcomes when compared to PHACO yet is likely to be more economical as it avoids the initial outlay of costs of PHACO. It is important to remember that the studies in this review were based in a variety of countries and situations (hospital based or cataract camps); a knowledge of the setting is vital before drawing conclusions from the data. 


\section{B A C K G R O U N D}

\section{Introduction}

The World Health Organization estimated from a recent global review of surveys that there are 37 million people worldwide who were blind in 2002 (Passolini 2004; Resnikoff 2004) and that agerelated cataract remained the leading cause of blindness globally in 2002 as it was in 1990. Fifty per cent of total world blindness is thought to be due to cataract and the majority of blinding cataract is found in developing countries. This is despite an increasing number of visually impaired and blind people gaining access to cataract surgical services due to the development of prevention of blindness programmes in many countries (Kupfer 1994). In India alone over three million cataract surgeries are now performed annually (Gupta 1998). Despite these positive trends the number of people blind due to cataract is increasing because of the changing demographic structure of populations (Limburg 1996; Minassian 1990; Thylefors 1998). More than $82 \%$ of all blind persons are 50 years of age or older. The contribution of cataracts to blindness globally is likely to grow due to an ageing population and unsuccessful attempts to control this blinding condition in low and middle-income countries (WHO 2005).

Blindness and severe visual impairment have a significant impact on the socioeconomic development of individuals and societies. Cataract surgical treatment leads to

substantial long-term savings in health-care and social expenditures. Savings also accrue from the reduced commitment made by family members caring for a visually impaired person. Females have a significantly higher risk of cataract blindness or being visually impaired than males mainly because of their higher incidence of cataract and inadequate access to eye health care, which is often provided preferentially to males (WHO 2005). The resulting downward socioeconomic spiral can be reversed through widely available, appropriate, cost-effective and curative interventions.

It is estimated that the present number of 20 million cataract blind will double by the year 2020. The global initiative "Vision 2020: The Right to Sight" has suggested various strategies to reduce cataract blindness (Foster 2001). The World Health Organization has called for a dramatic increase in surgical volumes worldwide, but the outcomes of cataract surgery are not always good and this needs to be investigated further (Venkatesh 2005).

\section{Treatment of cataract}

Opacification of the lens occurs as a result of denaturation of lens proteins and this is not thought to be reversible. Some interventions for preventing or delaying the development of cataract are used but their effectiveness has not been proven. Surgery is currently the only treatment option once the lens has opacified and vision is decreasing.

Intracapsular cataract extraction (ICCE) gained popularity in the 1960 s and 1970s (Elder 1969) and is still widely used in developing countries. The whole lens with intact capsule is removed from the eye. The function of the removed lens can be replaced either by the insertion of an intraocular lens (IOL) usually in the anterior chamber, or by the use of aphakic glasses or contact lens. The main advantage of ICCE is that it is a standardised technique that can be performed by trained surgeons rapidly (three to five minutes) with minimal manipulation of the eye. The secondary problem of opacification of the lens capsule, with the need for further surgical or laser intervention, is avoided with this technique.

Extracapsular cataract extraction (ECCE) was introduced with the development of microsurgical techniques in the early 1980 s. The lens contents are removed through a large $12 \mathrm{~mm}$ incision leaving the posterior lens capsule intact. A posterior chamber IOL can then be placed in the capsular bag (Apple 1989; Duane 1986). If no IOL is implanted, aphakic glasses or contact lenses must be used. Extracapsular surgery has become the preferred method of extraction in economically advantaged countries and most surgeons in developing countries have been trained to use this method.

Further technological development has led to a majority of surgeons in developed countries adopting sutureless ECCE surgery (Norregaard 1999). This surgery uses either mechanical fragmentation (phacoemulsification) of the lens nucleus (Mehta 1999), or a manual fragmentation technique (Blumenthal 1992; Hennig 1999). Both suture and sutureless ECCE leave in place the posterior capsule of the lens. This keeps the anatomical barrier between the posterior and anterior segments of the eye and may reduce the risk of posterior segment complications. The disadvantage of all the extracapsular techniques is that the posterior lens capsule can become cloudy (Apple 1992) with the need for a primary or secondary capsulotomy by surgery or using a YAG laser. This increases the costs of surgery and incurs the risk of secondary complications (Javitt 1992).

Phacoemulsification is the most commonly performed method of cataract extraction in the developed world and involves ultrasonic fragmentation of the crystalline lens. The incision is small $(3.2 \mathrm{~mm})$ which allows rapid visual rehabilitation postoperatively and low induced astigmatism. This technique requires a phacoemulsification machine which may cost $£ 20,000$ to $£ 45,000$ and has high disposable and maintenance costs. Phacoemulsification requires extensive surgical training, particularly the necessity to carry out a continuous capsulorhexis.

Manual small incision cataract surgery (MSICS) was first described by Blumenthal (Blumenthal 1994). In Asia and Africa there has been a renewal of interest in this technique (Ruit 2000) as an alternative to phacoemulsification because it is considerably less costly but has similar benefits of rapid visual recovery and reduced astigmatism (Yorston 2005). It involves a 6 to $6.5 \mathrm{~mm}$ scleral incision, just large enough to allow insertion of a $6 \mathrm{~mm} \mathrm{IOL}$. There are various different techniques described for performing the capsulotomy in MSICS, for example, the can-opener method (Gogate 2005), the continuous curvilinear capsulorhexis (PUNE) and the endocapsular technique where the incision is from pupil margin to pupil margin. The cataract is delivered into the anterior chamber hydroextracted and aspirated. The posterior capsule of the lens is left intact. This technique is technically more difficult than a standard manual ECCE.

In addition there is a growing realisation that substantial barriers to surgery still exist, especially in rural areas of developing countries (Fletcher 1999; Snellingen 1998; Vaidyanathan 1999). This complex mix of rapid development of technology, increasing numbers of people blind due to cataract, and barriers to surgery will demand the development of quality information systems, which can monitor outcomes and develop comparative cost models, accessible to both providers and consumers. 


\section{O B JECTIVES}

The aim of this review was to examine the effects of the main types of surgery currently used to treat age-related cataract.

\section{METHODS}

\section{Criteria for considering studies for this review}

\section{Types of studies}

This review included randomised controlled trials only.

\section{Types of participants}

Participants in the trials were people with age-related cataract.

\section{Types of interventions}

We included the following interventions in this review:

- phacoemulsification with a posterior chamber lens implant;

- manual small incision cataract surgery with a posterior chamber lens implant;

- extracapsular extraction with or without a posterior chamber intraocular lens implant;

- intracapsular extraction with or without an anterior chamber intraocular lens implant.

We also considered the different ways in which the lens may be removed in extracapsular extraction. We defined these as:

- techniques requiring the placement of sutures;

- techniques not requiring the placement of sutures with the lens removed after phacoemulsification or manual fragmentation.

\section{Types of outcome measures}

\section{Primary outcomes}

The primary outcome for this review was:

(1) Late postoperative visual acuity at one year or more after surgery in all studies presented as:

(a) the proportion of people with a poor visual outcome after surgery - defined as best corrected vision of worse than $6 / 60$ in the operated eye $(B C V A<6 / 60)$;

(b) the proportion of people not achieving good functional vision - good functional vision is defined as vision better than or equal to $6 / 18$ in the operated eye with usual spectacle correction.

\section{Secondary outcomes}

Secondary outcomes for this review include:

(2) Early postoperative visual acuity at 4 to 12 weeks after surgery presented as:

(a) the proportion of people with a poor visual outcome after surgery - defined as best corrected vision of worse than $6 / 60$ in the operated eye $(B C V A<6 / 60)$;

(b) the proportion of people not achieving good functional vision - good functional vision is defined as vision better than or equal to $6 / 18$ in the operated eye with usual spectacle correction;

(3) complications during surgery, for example, capsular rupture with or without vitreous loss, iris prolapse and early postoperative complications such as postoperative inflammation;

(4) complications at one year or more after surgery including the proportion of participants with retinal detachment, glaucoma, cystoid macular oedema, corneal decompensation, posterior capsule opacification;

(5) corneal endothelial cell loss;

(6) visual function other than visual acuity (visual perception, peripheral vision, sensory adaptation, depth perception);

(7) quality of life (self-care, mobility, social and mental function);

(8) costs.

\section{Search methods for identification of studies}

\section{Electronic searches}

We identified trials from the Cochrane Central Register of Trials - CENTRAL (which contains the Cochrane Eyes and Vision Group Trials Register) on The Cochrane Library, MEDLINE, EMBASE and the National Research Register (NRR).

See:Appendices for details of search strategies for each database.

\section{Searching other resources}

We searched the reference lists of identified included studies. We contacted study authors and other experts in the field to identify unpublished studies or studies sent for publication or in press. There were no language restrictions in the searches for trials.

\section{Data collection and analysis}

\section{Selection of trials}

Two review authors independently screened the titles and abstracts resulting from the electronic searches. Full copies were obtained of any report referring to definitely or possibly relevant trials. These full copies were assessed according to the definitions in the 'Criteria for considering studies for this review'. Only trials meeting these criteria were assessed for methodological quality.

\section{Assessment of methodological quality}

Trial quality was assessed according to methods set out in section 6 of the Cochrane Handbook for Systematic Reviews of interventions (Higgins 2005b). Five parameters were considered: allocation concealment, method of allocation to treatment, documentation of exclusions, completeness of follow-up, methods of documentation of complications. Each parameter of trial quality was graded: A - low risk of bias; $\mathrm{B}$ - moderate risk of bias; $\mathrm{C}$ - high risk of bias. Two review authors independently assessed the trial quality and disagreement was resolved by discussion. Authors were not masked to the report authors and trial results during the assessment.

\section{Data collection}

Data were extracted using a form developed by the Cochrane Eyes and Vision Group. Two authors extracted data and compared the results for differences. Discrepancies were resolved by discussion.

\section{Data synthesis}

Data from studies collecting comparable outcome measures with similar follow-up times were analysed using either the risk ratio, odds ratio or weighted mean difference. Where it was appropriate to pool results we used a fixed-effect model because of the low number of trials in each comparison. We assessed heterogeneity between trial results using a chi-square test. If the studies showed quite different results we did not combine them, even though the test for heterogeneity was not significant, as we felt that it would have low power in these situations.

\section{Sensitivity analysis}


We planned to conduct sensitivity analyses to assess the effect of study quality on effect size. There are not enough trials included at present to conduct any sensitivity analyses.

\section{Updating the review}

The original protocol only looked at studies with postoperative visual acuity results at one year or more. A modification was made to this protocol to include studies looking at postoperative visual outcome at six weeks and beyond. The authors updating the review felt that early visual stabilisation is achieved with certain surgical techniques: phacoemulsification and manual small incision surgery. These studies were carried out in countries where longer term follow up is difficult (George 2005; Gogate 2005; PUNE) or when it does occur there is a large loss to follow up (LAHAN). It cannot be said that the visual outcome at four to 12 weeks is a perfect representation of long term outcome as we need to take account of later onset adverse events.

Early visual stabilisation is not achieved for surgical techniques involving sutures such as ECCE where the visual outcome at six weeks is affected by suture induced astigmatism (MEHOX).

\section{RES U L T S}

\section{Description of studies}

The original electronic searches found a total of 2824 reports. We obtained the full copy of nine reports of trials that appeared to meet our inclusion criteria. We excluded three of these trials (Alpar 1984; De Laage 1988; Quentin 1993) (see the Characteristics of excluded studies table) and included six (LAHAN; MEHOX; MIOLS; OCTET; SACMS; Vogel 1993).

\section{Updated searches}

We updated the searches in October 2005 and new reports were screened for inclusion. We obtained the full copy of 20 reports of trials that appeared to meet our inclusion criteria. We excluded nine of these (Bomer 1995; Bourne 2003; Ford 2005; Hsu 2005; Jurgens 1997; Leen 1993; Loo 2004; Noske 1988; Ruellan 1994) (see the 'Characteristics of excluded studies' table) and included 11 trials (Chee 1999; Dowler 2000; George 2005; Gogate 2005; Katsimpris 2004; Landau 1999; Laurell 1998; PUNE; Ravalico 1997; Rizal 2003; Waddell 2004). The searches were again updated in August 2006 and out of 53 new reports of trials; we have identified three that may meet our inclusion criteria and are waiting further review assessment (Guo 2005; Liang 2006; Parmar 2006).

\section{Results of the search}

A summary of the included studies is presented below. Further details can be found in the 'Characteristics of included studies' table.

\section{Included studies}

\section{Types of participants and settings}

Size of study

The 17 included trials can be divided into three groups depending on size of study:

- seven smaller trials (less than 100 participants): Chee 1999, Dowler 2000, Katsimpris 2004, Landau 1999, Laurell 1998, Ravalico 1997, Rizal 2003;

- seven intermediate trials (101 to 999 participants): George 2005, Gogate 2005; MEHOX, OCTET, PUNE, Vogel 1993, Waddell 2004;
- three larger trials (more than 1000 participants): LAHAN; MIOLS; SACMS.

\section{Location of study}

It should also be noted that these trials were conducted in different regions of the world and the participants were recruited from various settings:

- in Europe: Dowler 2000 (tertiary eye hospital), Katsimpris 2004 (general hospital), Landau 1999 (eye hospital), Laurell 1998 (eye hospital), MEHOX (2 centres: tertiary eye hospital, teaching hospital), OCTET ( teaching hospital), Ravalico 1997 (university hospital), Vogel 1993 (university hospital);

- in the Far East: Chee 1999 (teaching hospital), Rizal 2003 (teaching hospital);

- in the Indian Subcontinent: George 2005 (community based eye hospital), Gogate 2005 (community based eye hospital), LAHAN (rural eye hospital), MIOLS (rural hospital and screening eye camps); PUNE (community based eye hospital), SACMS ( 3 centres: rural eye hospital, national training hospital, eye camps);

- in Africa: Waddell 2004 (rural outreach clinics).

Clinical subgroups (for inclusion and exclusion criteria, see the participants section in the 'Characteristics of included studies' table) Dowler 2000: This study was conducted on diabetic patients only. Katsimpris 2004: All the patients in this study had pseudoexfoliation, small pupil and small to moderate phacodenesis, which is known to be a complicated subgroup of cataract patients that was often excluded from other study populations.

Waddell 2004: This study was carried out in Africans, prolonged iritis is known to occur in this patient subgroup (Johnson 2000)

\section{Age of Participants}

The majority of trials recruited participants aged 40 years and above, with the exception of OCTET, Ravalico 1997 and Vogel 1993 where participants were aged over 55 years and Landau 1999 and Laurell 1998 where the participants were aged over 68 years.

\section{Types of interventions}

Two studies compared intracapsular extraction with aphakic glasses to intracapsular extraction with an anterior chamber lens (LAHAN; SACMS). Two studies compared intracapsular extraction with aphakic glasses or anterior chamber intraocular lens to extracapsular extraction with a posterior chamber lens (MIOLS; Waddell 2004). Phacoemulsification has been compared with extracapsular cataract surgery in nine trials (Chee 1999; Dowler 2000; George 2005; Katsimpris 2004; Landau 1999; Laurell 1998; MEHOX; Ravalico 1997; Rizal 2003). Two studies compared phacoemulsification with manual small incision cataract surgery (George 2005; Gogate 2005). Two studies compared extracapsular cataract surgery with manual small incision cataract surgery (George 2005; PUNE). Two studies used lens types that are no longer in use either because of unacceptable complications or because the lens has been replaced by an improved model (OCTET; Vogel 1993). Data for these studies are presented separately.

\section{Follow-up}

Follow-up ranged from one month (Ravalico 1997) to five years (LAHAN). 


\section{Outcomes}

Distance visual acuity was measured in all trials using either Snellen acuity or LogMAR scale with the EDTRS chart. Clinical complications were usually presented. Endothelial cell loss was assessed in five studies (George 2005; MEHOX; OCTET; Ravalico 1997; SACMS). Postoperative inflammation was reported in four studies (Chee 1999; Dowler 2000; Laurell 1998; Ravalico 1997). Cost analysis was assessed in three studies (MEHOX; PUNE; Rizal 2003).

\section{Risk of bias in included studies}

\section{Method and concealment of allocation to treatment}

Six trials state that they used computer generated random number lists as the method of producing a random sequence (Dowler 2000; George 2005; Landau 1999; Laurell 1998; Rizal 2003, Waddell 2004). Two trials state that allocation schedules were allocated by the trial statisticians (Gogate 2005, MEHOX).

The method of concealment used to deliver the sequence of treatment allocation in six studies was sealed opaque envelopes (Gogate 2005; LAHAN; MEHOX; MIOLS; SACMS; Waddell 2004) and in one study ballots were drawn (PUNE). The delivery system for concealment of allocation was not stated in Dowler 2000, George 2005, Landau 1999; Laurell 1998 and Rizal 2003.

For the other trials, it is simply stated that the groups were randomly allocated and details of method and delivery of randomisation were not stated (Chee 1999; Katsimpris 2004; OCTET; Ravalico 1997; Vogel 1993).

\section{Documentation of exclusions}

There were no exclusions after treatment allocation in ten trials (Chee 1999; Dowler 2000; Gogate 2005; LAHAN; Landau 1999; MIOLS; OCTET; PUNE; Ravalico 1997; Rizal 2003). In two trials, eight people did not receive surgery after treatment allocation (SACMS; Waddell 2004). In MEHOX five people in the phacoemulsification group were withdrawn after randomisation compared to 13 in the extracapsular group. Exclusions were not clearly documented in the other trials (George 2005; Katsimpris 2004; Laurell 1998; Vogel 1993).

\section{Completeness of follow-up}

Follow-up rates were good. More than $85 \%$ follow up was achieved in ten studies at time of conclusion (Dowler 2000 100\%; George 2005 85\%; Gogate 2005 92.5\% (phacoemulsification group): 93.5\% (manual small incision cataract surgery group (MSICS)); LAHAN 91\% (in both groups); MEHOX $89 \%$ (phacoemulsification group): $86 \%$ (extracapsular group); OCTET 99\%; PUNE 94.5\% (extracapsular group): 96.1\% (MSICS group); Ravalico 1997 100\%; Rizal 2003 100\%; Waddell 2004 89\%). In three studies there was more than $80 \%$ follow up at study conclusion (Landau 1999; Laurell 1998; SACMS $84 \%$ in both groups). In MIOLS $87 \%$ of the group receiving an intraocular lens (IOL) and $82 \%$ of the group receiving aphakic spectacles were followed up. In three trials the number of patients seen at last follow up was not clear (Chee 1999; Katsimpris 2004; Vogel 1993). In general trials did not report whether people who were lost to follow-up differed from those who remained in the trial.

\section{Masking of outcome assessment}

This involved masking of the patients and the assessors to type of surgery that had been performed in each treatment group. For masking of outcomes, see the methods section in the 'Characteristics of included studies' table.

In trials where an IOL was compared to aphakic spectacles/contact lenses (LAHAN; MIOLS; OCTET; SACMS) or posterior chamber IOL compared to anterior chamber IOL (Vogel 1993; Waddell 2004), masking of outcome assessment was not possible because of the spectacle appearance of participants in either arm or the type of $\mathrm{IOL}$ was obvious from examination of the eye. As in many surgical trials despite the assessors being masked to the treatment allocation code it was usually obvious which intervention the participant had undergone. In the trials comparing phacoemulsification and extracapsular extraction, participants were said to be masked to the study group but the assessors were either unmasked (Dowler 2000; Katsimpris 2004; MEHOX; Ravalico 1997; Rizal 2003) or other studies state that their assessors was masked (Chee 1999; George 2005; Laurell 1998; Landau 1999) depending on what assessment was being performed. Despite some studies stating that the assessor was masked when comparing PHACO and ECCE it seems difficult for this to have been done as the size, location and suture number in each procedure is obviously different. The studies involving MSICS were also said to have masked assessors (George 2005; Gogate 2005; PUNE) which may have been more likely with the MSICS and PHACO groups but it would have been obvious at clinical assessment which were the ECCE group. In most of these studies masking was carried out as much as was possible for outcomes such as refraction, visual acuity assessment, endothelial cell counts, UBM and fluorescein angiograms which were performed by assessors other than those who were carrying out the postoperative clinical examination.

\section{Intention-to-treat analysis}

Fourteen trials analysed all participants who completed follow-up in the group to which they were randomised (Chee 1999; Dowler 2000; George 2005; Gogate 2005; Katsimpris 2004; LAHAN; Landau 1999; Laurell 1998; MEHOX; MIOLS; PUNE; SACMS; Ravalico 1997; Rizal 2003). In the OCTET study it was not clear if this was done. The analysis was complicated by the fact that for a small minority of participants, both eyes were enrolled in the trial. In Waddell 2004 data was analysed both as per randomisation and also by IOL implanted.

\section{Handling of data for two eyes}

In most of the trials, only one eye per person was enrolled in the trial, thus avoiding difficulties with the analysis of correlated data for two eyes (Chee 1999; George 2005; Gogate 2005; Katsimpris 2004; LAHAN; Landau 1999; Laurell 1998; MEHOX; MIOLS; PUNE; SACMS; Ravalico 1997; Rizal 2003). In OCTET 333 eyes from 331 people were enrolled in the trial. Some people were therefore in more than one treatment group. Since it affects only a small number of eyes it is considered unlikely to have a major effect on the results and this complexity was therefore ignored in the analysis. Two studies were paired eye studies (Dowler 2000; Waddell 2004) and were not compared to results from non-paired eye studies.

\section{Effects of interventions}

We used the following abbreviations for this section :

$\mathrm{ACIOL}$ - anterior chamber intraocular lens

AG - aphakic glasses

BSCVA - best spectacle corrected visual acuity

BCVA - best corrected visual acuity

CSME - clinical significant macular oedema

$\mathrm{CV}$ - coefficient of variation

ECC - endothelial cell count

ECCE - extracapsular cataract extraction 
ICCE - intracapsular cataract extraction

$\mathrm{IOL}$ - intraocular lens

MSICS - manual small incision cataract surgery

$\mathrm{PCIOL}$ - posterior chamber intraocular lens

PCO - posterior capsular opacification

PHACO - phacoemulsification

RCT- randomised controlled trials

SIA - surgical induced astigmatism

UBM - ultrasound Biomicroscopy

UCVA - uncorrected visual acuity

\section{(1) PHACO WITH PCIOL VERSUS ECCE WITH PCIOL}

We found nine trials that compared these types of surgery (Chee 1999; Dowler 2000; George 2005; Katsimpris 2004; Laurell 1998; Landau 1999; MEHOX; Ravalico 1997; Rizal 2003).

\section{(a) visual outcomes}

Seven studies reported on the visual outcome following surgery. However, due to the heterogeneity of the data presentation and the variability in the postoperative time interval at which visual outcomes were reported, see Table 1, we were unable to put them in a meta-analysis. We have referred back to the authors to get further details of the data. MEHOX reported visual outcomes (both BSCVA and UCVA) measured at three weeks, six weeks, three months, six months and one year after surgery. The phacoemulsification group achieved a better visual outcome throughout the follow-up period due to the fact that the extracapsular group experienced higher levels of astigmatism. One year after surgery, 204/224 (91\%) of the phacoemulsification group achieved visual acuity of $6 / 9$ or better with spectacle correction, compared to $184 / 215$ (86\%) of the extracapsular group (relative risk (RR) 1.06, 95\% confidence interval (CI) 0.99 to 1.14) This is similar to Dowler 2000 (study population of diabetics only and a paired eye study) where $96 \%$ (44/46) of the phacoemulsification group and $83 \%(38 / 46)$ achieved visual acuity of $6 / 12$ or better with spectacle correction at one year. Katsimpris 2004 (study population of pseudoexfoliative cataracts with small pupils) documented significantly better BSCVA at one year in the phacoemulsification group than extracapsular group. Chee 1999; George 2005, Laurell 1998 and Ravalico 1997 showed no significant difference in BSCVA between the two groups at respective follow up times. The BCVA for the seven studies are summarised in Table 2. Two studies commented on UCVA. In the MEHOX study one year after surgery, $87 / 224$ (39\%) of the phacoemulsification group achieved unaided visual acuity of $6 / 9$ or better compared to $42 / 215$ (20\%) of the extracapsular group (RR $1.99,95 \% \mathrm{Cl} 1.45$ to 2.73 ). In Chee $199983 \%$ of phacoemulsification group achieved 6/12 or better compared to $50 \%$ in the extracapsular group at two months.

\section{(b) complications during surgery}

In the two largest studies there were significantly more complications in the extracapsular group. In the MEHOX study, $7.2 \%(17 / 236)$ of the extracapsular group had peroperative iris prolapse compared to zero of the phacoemulsification group. Capsule rupture and/or vitreous loss were equally common in the two groups with $8 / 246$ cases in the PHACO group compared to 9/236 cases in ECCE group. In the Katsimpris 2004 study there was a significantly higher rate of zonular dialysis, capsular tear, and vitreous loss in the extracapsular group. Complications are not commented on in two studies Dowler 2000 and Ravalico 1997 and in four studies (Chee 1999; George 2005; Landau 1999; Laurell 1998) it is clearly stated that there were no intraoperative complications.
Complications during surgery are statistically compared in Analysis 1.2.

\section{(c) clinical complications}

In MEHOX corneal decompensation was not reported but there were two retinal detachments, both in the PHACO group, and five cases of macular oedema (two in the PHACO group and three in the ECCE group). In Katsimpris 2004 there was less macula oedema $(2.1 \% \vee 16.8 \%)$ in the PHACO group compared to ECCE group. It was not possible to ascertain from the papers whether the same patients who had PC tear +/- vitreous loss were the same as those who developed macula oedema. We have statistically compared the macula oedema rates in Analysis 1.1. There was no difference in IOL decentration between the two groups. Landau 1999 found a significantly higher rate of intraocular lens haptic subluxation in the extracapsular group. Three studies commented on the development of posterior capsule opacification (PCO), one was a paired eye study (Dowler 2000), and other two were single eye studies (Katsimpris 2004; MEHOX). MEHOX showed posterior capsule opacification occurred less commonly in the PHACO group (RR $0.67,95 \% \mathrm{Cl} 0.48$ to 0.92). Katsimpris 2004 showed there was significant less posterior capsule opacification $(10.6 \% \vee 38.3 \%)$ in patients who underwent PHACO who had pseudoexfoliation syndrome and Dowler 2000 found a higher rate of posterior capsule opacification in the extracapsular group (35\% $v 11 \%$ ) in diabetic patients. The population subgroups of these three studies are not comparable so an overall analysis of PCO was not carried out. Dowler 2000 found no significant difference between the two groups with respect to postoperative incidence of pseudophakic macula oedema (four cases PHACO versus six ECCE cases), postoperative incidence of progression of diabetic retinopathy or development of high-risk proliferative diabetic retinopathy. Three studies showed significantly more inflammation in the ECCE group in the early postoperative period but no difference at three months (Chee 1999; Dowler 2000; Laurell 1998). Although the time interval at which postoperative inflammation is recorded are similar in the three studies the data is recorded in different formats, qualitative (Dowler 2000), expressed as median and interquartile range (Laurell 1998) and mean and standard deviation (Chee 1999), hence we have been unable to compare them statistically. We have contacted the authors of these studies to request the raw data to undertake the appropriate analysis. Corneal decompensation was not reported.

\section{(d) corneal endothelial cell dysfunction}

Corneal endothelial cell loss was reported in three studies. However, due to the heterogeneity in follow up time (Ravalico 1997 - 30 days, George 2005 - 6 weeks, MEHOX - 1 year) it was not possible to compare them statistically. We have contacted the authors of the latter study to request the raw data at six weeks to undertake the appropriate meta-analysis.

Ravalico 1997 showed a significant increase in endothelial permeability, corneal thickness and coefficient of variation in the early postoperative period in the extracapsular group. Three studies have shown no difference in mean percentage endothelial cell loss between the two groups at respective follow up times (George 2005 (4.72\% ECCE v 5.41\% PHACO), Ravalico 1997 (10.1\% ECCE v 8.5\% PHACO), MEHOX (9.1\% ECCE v $10.5 \%$ PHACO). In the MEHOX study however PHACO was associated with a higher risk of severe cell loss in patients with hard cataract ( $P=0.04$ RR 3.7, 95\% $\mathrm{Cl} 1.03$ to 13.34 ). 
(e) costs

Two studies have looked at cost in different economic settings. In the MEHOX study in the UK, the average cost of PHACO was similar to ECCE i.e. $£ 332.89$ compared to $£ 335.07$. Rizal 2003 in Malaysia found ECCE to be significantly cheaper than PHACO i.e. RM 1,664.46 (RM $1,233.04$ to RM 2,377.64) v RM 1,978.00 (RM 1,557.87 to RM $3,334.50$ ). However, the follow up was short (only 2 months) and the study did not include future clinic visits for removal of sutures.

\section{(2) PHACO WITH PCIOL VERSUS MSICS WITH PCIOL}

Two studies have compared this intervention (George 2005; Gogate 2005).

\section{(a) visual outcomes}

In Gogate 2005 1.6\% (3/185) of the PHACO group and 1.6\% (3/187) of the MSICS group had BCVA worse than 6/18 i.e. did not achieve functional vision at 6 weeks RR $1.01(95 \% \mathrm{Cl} 0.21$ to 4.94$)$. $0.5 \%$ of the PHACO group and $0 \%$ of the MSICS group have a poor outcome following surgery (BSCVA < 6/60). In the George 2005 study there was only 1 patient with BSCVA worse than $6 / 18$ (who was in the MSICS group). We have statistically compared the visual outcomes in Analysis 2.1 and Analysis 2.2.

\section{(b) complications during surgery}

Gogate 2005 showed 7/199 (3.5\%) of the PHACO group and 12/201 $(6 \%)$ of the MSICS had PC tears $(P=0.43)$. Both groups had 2 patients with iridodialysis and 1 with zonule dialysis. One patient in the PHACO group had a drop nucleus and one in the MSICS group had a detachment of Descemet's membrane. Two patients in the PHACO group had an extension of their anterior capsulorhexis and another 2 had to convert to MSICS due to intraoperative difficulty. There were no intraoperative complications from the George 2005 study. The PC tear/ vitreous loss are statistically compared in Analysis 2.3.

\section{(c) clinical complications}

From Gogate 20054 (PHACO) v 5 (MSICS) patients developed iritis postoperatively. Nine per cent (18/185) PHACO and 4.5\% (9/187) MSICS ( $P=0.073$ ) developed corneal oedema on the first day which had resolved by 6 weeks in both groups. Three patients developed a shallow anterior chamber on day 1 (1 PHACO, 2 MSICS). Three patients in the PHACO and 4 in the MSICS had retained cortical matter. There was no documentation about postoperative complications in George 2005.

\section{(d) corneal endothelial cell count}

George 2005 showed no statistically significant difference in endothelial cell loss between the two groups. The sample size of the study was adequate to detect a difference of $7 \%$ in endothelial cell loss between techniques with a power of $80 \%$. There was a mean $5.41 \%(\mathrm{~N}=60, \mathrm{SD} 10.99)$ induced cell loss in PHACO at 6 weeks follow-up compared with $4.21 \%(N=53, S D 10.29)$ for MSICS.

\section{(3) ECCE WITH PCIOL VERSUS MSICS WITH PCIOL}

Two studies have compared this intervention (George 2005; PUNE).

\section{(a) visual outcomes}

In the PUNE study $13.3 \%(48 / 362)$ of the ECCE group and 10.2 $\%(35 / 344)$ of the MSICS group had a BSCVA < 6/18 i.e. a poor functional visual outcome in the operated eye RR $1.30(95 \% \mathrm{Cl} 0.86$ to 1.96), there was no significant difference between the two groups (see Analysis 3.2). Four patients (1.1\%) in ECCE group and 6 (1.7\%) in MSICS group had poor visual outcome (BSCVA <6/60) in the operated eye, there was no significant difference between the two groups. In George 2005 1/53 cases had BSCVA < 6/18 in MSICS group compared to 5 in the ECCE group ( 3 related to high astigmatism, 1 posterior capsule opacification and 1 anterior ischaemic optic neuropathy). Only one patient, had a VA $<6 / 60$ and they were in the ECCE group (see Analysis 3.1).

(b) complications during surgery

In the PUNE study, 21 of the patients in the MSICS group were converted to ECCE either due to density of cataract or because of small pupil. Seventeen of the ECCE group and 29 of the MSICS group had intraoperative complications RR 1.04 (95\% $\mathrm{Cl} 1$ to 1.08$)$ this was not significantly different. Ten out of 383 ( 6 with vitreous loss) in the ECCE group and 18/358 (6 with vitreous loss) in the MSICS had posterior capsule tears OR $0.51(95 \% \mathrm{Cl} 0.23$ to 1.11$)$ (see Analysis 3.3). Two patients in the MSICS group had iridodialysis. There were no complications during surgery in the George 2005 study (we have reaffirmed this by contacting the author).

\section{(c) clinical complications}

In the PUNE study $94 / 383$ in the ECCE group and $121 / 358$ in the MSICS group had postoperative complications in the first 6 weeks RR $1.14(95 \% \mathrm{Cl} 1.04$ to 1.25$)$; the majority were mild $(27.1 \%)$ (OCTET grade 1). There were no severe complications (OCTET grade 3), moderate complications were seen in 3/383 ECCE group and $5 / 358$ in the MSICS group RR $1.01(95 \% \mathrm{Cl} 0.99$ to 1.02$)$, there was no significant difference between the two groups. Mild complications e.g. descemet's folds, iritis and corneal oedema were more commonly seen in MSICS group (32.4\% v 23.7\% ECCE group). Posterior capsule opacification was seen equally in both groups (3/383 ECCE v 4/358 MSICS).

\section{(d) corneal endothelial cell count}

The George 2005 study showed there was no statistically significant difference in endothelial cell loss between the two groups. The sample size was adequate to detect a $7 \%$ difference in endothelial cell count between the groups, giving a power of $80 \%$. There was a mean $4.72 \%(\mathrm{~N}=52, \mathrm{SD} 13.07)$ induced cell loss in ECCE at 6 weeks follow-up compared with $4.21 \%$ ( $N=53$, SD 10.29) for MSICS.

\section{(e) costs}

In the PUNE study there was no significant difference in surgical time or cost between the two procedures, even accounting for surgeon variation. The average cost of ECCE was US $\$ 15.82$, MSICS US $\$ 15.68$ of which US $\$ 11.34$ was a fixed facility cost common to both. It is not clear from the paper the power of this study to detect a difference in costing with this sample size hence we have contacted the authors to clarify this.

\section{(4) ECCE WITH PCIOL VERSUS ICCE WITH ACIOL}

One study compared this intervention (Waddell 2004).

\section{(a) visual outcomes}

The proportion not achieving good functional vision following surgery was $18 \%$ in the $\mathrm{ACIOL}$ group and $16 \%$ in the $\mathrm{PCIOL}$ group RR 1.13 (95\% Cl 0.61 to 2.08). The difference was not statistically significant. Eleven per cent of patients with $\mathrm{ACIOL}$ and $9 \%$ of patients with $\mathrm{PCIOL}$ had a poor visual outcome following surgery RR 1.22 (95\% Cl 0.53 to 2.82 ). There was no significant difference in the final refractions between the two groups. In this study no biometry was performed, patients received standard power lens.

\section{(b) complications during surgery}


There was no difference in overall incidence of complications between the two groups. Nine eyes randomised to PCIOLs were converted to $\mathrm{ACIOL}$ because of capsule rupture or zonule dehiscence at surgery, 1 eye randomised to $\mathrm{ACIOL}$ inadvertently received a $\mathrm{PCIOL}$.

\section{(c) clinical complications}

Twelve eyes that received $\mathrm{ACIOL}$ underwent secondary procedures; 8 had removal of post-inflammatory membranes, 3 had repeat peripheral iridectomy due to iris bombé, 1 had replacement of displaced lens. Five eyes that received PCIOLs had secondary procedures. Three had removal of thickened anterior capsule flap, 2 had removal of residual lens matter. Non-surgical interventional complications occurred in 5 eyes with $\mathrm{ACIOL}$ and 3 eyes with $\mathrm{PCIOL}$. In the ACIOL group, 3 had iris bombé, 1 developed an anterior chamber blood clot and one developed a hypopyon. In the PCIOL group 2 eyes developed posterior capsule thickening, 1 eye developed a postoperative anterior chamber blood clot. This study only addresses $\mathrm{IOL}$ implants in African patients hence the degree of inflammation cannot be extrapolated to patients from other ethnic groups.

\section{(5) ECCE WITH PCIOL VERSUS ICCE WITH AG}

One trial compared these types of surgery (MIOLS).

\section{(a) visual outcomes}

Best-corrected vision less than $6 / 60$ occurred in $0.6 \%$ of the ECCE$\mathrm{PCIOL}$ group compared to $1.6 \%$ of the ICCE-AG group. People in the ECCE-PCIOL were less likely to experience a poor outcome one year after surgery (RR $0.39,95 \% \mathrm{Cl} 0.18$ to 0.84 ). Functional vision less than $6 / 18$ was recorded in $16 \%$ of people receiving IOLs and $15 \%$ of people receiving spectacles (RR $1.08,95 \% \mathrm{Cl} 0.91$ to 1.28 ). This analysis includes 155 participants who did not present with personal eye glasses at follow-up.

\section{(b) complications during surgery}

Vitreous loss during surgery was reported in $1.7 \%$ of participants in the MIOLS. Capsular rupture combined with vitreous loss was observed in $1.7 \%$ of the ECCE-PCIOL group.

\section{(c) clinical complications}

Posterior capsular opacification occurred in 9\% of the ECCE$\mathrm{PCIOL}$ group at one year. There were eight cases of corneal decompensation, four in each group and eight cases of retinal detachment, three in the ECCE-PCIOL group compared to five in the ICCE-AG group. Macular oedema, the diagnosis of which was verified with fluorescein angiography, occurred more frequently in the ICCE-AG group. There were $23 / 1474$ in the ECCE-PCIOL group compared to $59 / 1401$ in the ICCE-AG group (RR $0.37,95 \% \mathrm{Cl} 0.23$ to $0.60)$.

\section{(d) quality of life}

The MIOLS study was the only study that examined quality of life. In both study groups participants' responses showed large improvements in visual functioning and quality of life. With improvement in visual acuity from 20/60 to 20/20 there was an increase in visual functioning and quality of life for both procedures with the advantage of ECCE with PCIOL over ICCE with AG across all visual categories. The visual functioning and quality of life subscale scores associated with lens implant visual acuity of 20/50 to $20 / 60$ showed consistently the same or slightly better than participants operated without lens implant associated with visual acuity scores of $20 / 20$.

\section{(6) ICCE WITH ACIOL VERSUS ICCE WITH AG}

Two trials compared these interventions (LAHAN; SACMS).

\section{(a) visual outcomes}

Best corrected vision worse than $6 / 60$ was reported in $2.6 \%$ of the ICCE-ACIOL group compared to $2.2 \%$ of the ICCE-AG group in the LAHAN study (RR $1.19,95 \% \mathrm{Cl} 0.66$ to 2.14 ). In SACMS with data up to two years after surgery, $3.9 \%$ of the ICCE-ACIOL group compared to $3.6 \%$ of the ICCE-AG group had best corrected acuity less than $6 / 60$ one year after surgery $(\mathrm{RR} 1.06,95 \% \mathrm{Cl} 0.57$ to 1.96$)$. The pooled relative risk from these two studies is $1.13,95 \% \mathrm{Cl} 0.74$ to 1.72 . The visual outcome BCVA worse than $6 / 60$ at one year is statistically compared in Analysis 4.1.

The whole cohort taking part in the LAHAN trial was invited for reexamination two to five years after surgery; $65 \%$ were re-examined. There were 13 new cases of best corrected acuity less than 6/60 occurring after one year follow-up, nine in the ICCE-ACIOL group and four in the ICCE-AG (odds ratio $2.1,95 \% \mathrm{Cl} 0.59$ to 9.55). There was no indication that lens-related problems increased over time.

Functional vision less than $6 / 18$ was reported in $55 \%$ of the ICCEACIOL group compared to $41 \%$ of the ICCE-AG group (RR 1.35, 95\% $\mathrm{Cl} 1.22$ to 1.49 ) in the LAHAN study. The visual outcome BCVA worse than $6 / 18$ at one year for the two studies is statistically compared in Analysis 4.2.

There were similar numbers of people severely visually impaired and blind in both groups at all follow-up times. The exception to this is at one year when there were more people functionally blind in the ICCE-AG. This occurred due to the loss of aphakic glasses. There was a $60 \%$ reduced risk of functional blindness in the ICCE$\mathrm{ACIOL}$ group one year after surgery. Significant astigmatism was approximately four times more common in the ICCE-ACIOL group compared to ICCE-AG group. Most participants in both groups had 'against the rule' astigmatism, 446 or $88.8 \%(95 \% \mathrm{Cl} 86.0$ to 91.6$)$ and 348 or $83.5 \%(95 \% \mathrm{Cl} 79.9$ to 87.1$)$ respectively.

In SACMS pre-operative assessment was not standardised as two centres used different types of biometry and one centre did not use biometry. In addition, the results were not presented strictly according to the definition of functional vision used in this review. Visual acuity was presented with the entire aphakic group having +10 spectacle correction. This analysis showed that $51 \%$ of the $\mathrm{ACIOL}$ group had functional vision less than $6 / 18$ compared to $46 \%$ of the aphakic group (RR 1.10, 95\% $\mathrm{Cl} 0.97$ to 1.24). As the outcome is not strictly the same in these two cases, we have not calculated an overall summary score. In the SACMS a limbal incision was used in $91 \%$ of patients. No comparative data are available on degree of astigmatism.

\section{(b) complications during surgery}

There were similar numbers of peroperative complications in the two groups in SACMS. Vitreous disturbance leading to vitrectomy occurred in $69 / 616$ (11.2\%) of the ICCE-ACIOL group compared to $58 / 613(9.5 \%)$ of the ICCE-AG group. In LAHAN $2.9 \%$ of the ICCE$\mathrm{ACIOL}$ group received an anterior vitrectomy compared to $0.4 \%$ of the ICCE-AG group.

\section{(c) clinical complications}

Corneal endothelial cell loss after six week follow-up was $17 \%$ in the IOL group and $14.4 \%$ in the aphakic group $(P<0.05)$ in the SACMS trial. After six weeks there was no significant difference in the continuing cell loss between eyes having no lens compared to 
eyes with lens ( 12 months: IOL 5.3\%, AG 4.1\%, P = 0.06; 24 months: IOL 3.1\%, AG 2.9\% P = 0.71).

The LAHAN and SACMS studies reported other complications related only to severe visual impairment. On the whole, these complications occurred infrequently. The power of these studies to detect differences, even when the results are pooled, is therefore low.

Retinal detachment: There were few cases of retinal detachment and so the power of these studies to detect a difference was low. At one year after surgery, there were $8 / 1430$ in the ICCE-AG groups and 2/1437 in the ICCE-ACIOL groups (pooled RR 0.29, 95\% CI 0.07 to 1.20 ). However, later follow-up in the LAHAN study found four more cases of retinal detachment in the ICCE-ACIOL group, further evidence for little difference between the two groups in incidence of retinal detachment.

Glaucoma: In LAHAN secondary glaucoma as a cause of visual loss was reported more commonly in the ICCE-ACIOL group (five cases) compared to the ICCE-AG group (no cases). Uveitis was also found more commonly in the ACIOL group compared with the aphakic group. SACMS reports the presence of secondary glaucoma at $0.1 \%$ with no significant difference between the groups.

Cystoid macula oedema: There were two cases of cystoid macular oedema in the ICCE-ACIOL group in LAHAN compared to none in the ICCE-AG group. In SACMS three cases in the ICCE-ACIOL group compared to two in the ICCE-ACIOL group. The pooled relative risk of having severe visual impairment due to cystoid macula oedema in the ICCE-ACIOL group compared to ICCE-AG group was 2.2 (0.49 to 9.79 ).

Corneal endothelial decompensation: This occurred rarely. In LAHAN there was one case at one year that occurred in the ICCEAG group. No further cases were identified after one year. In SACMS there was one case in the IOL group.

The clinical complications for retinal detachment, macular oedema and corneal decompensation are statistically compared in Analysis 4.3.

\section{(7) STUDIES OF OLDER LENS TYPES}

There were two studies that considered older lens types (OCTET; Vogel 1993). The data for these studies are not presented in the meta-analyses.

\section{(a) visual outcomes}

Best-corrected vision of less than 6/60 was not reported as an outcome in the OCTET study. In this study, $96 \%$ of ICCE without IOL, $84 \%$ of ICCE with iris clip lens and $84 \%$ of ECCE with iridocapsular lens had best corrected vision better or equal to $6 / 12$ at one year after surgery. In Vogel 1993 the vision outcomes at two years after surgery were presented as medians and mean. There was a nonsignificant difference between the two study groups. In the ICCEACIOL group the mean visual acuity was 0.72 (standard deviation 0.237 ) compared to 0.74 (standard deviation 0.194) in the ECCE$\mathrm{PCIOL}$ group.

\section{(b) complications during surgery}

Vitreous loss was reported in $4 \%$ of cases in OCTET. Capsular rupture was reported in $2.5 \%$ of OCTET cases. The study found a total cell loss of $14.9 \% 24$ months after surgery. There was a significantly higher continuing cell loss with the iridocapsular lens

Surgical interventions for age-related cataract (Review)

Copyright @ 2009 The Cochrane Collaboration. Published by John Wiley \& Sons, Ltd. compared to the iris clip lens or no lens implantation. Many of these corneas decompensated two years after surgery.

\section{(c) clinical complications}

Vogel 1993 reports the presence of secondary glaucoma of $1.2 \%$. Cystoid macula oedema is reported in both studies. Only Vogel 1993 verified the findings with fluorescein angiography. Posterior capsular opacification was reported in the three studies that included an ECCE group and was the most frequent complication relating to visual impairment (all grades of impairment) ranging from $0.5 \%$ at one year and $13.5 \%$ at four years (in a random subsample) in the MIOLS study to $29.6 \%$ in the Vogel 1993 study. Vogel 1993 also reported a 3.1\% frequency of toxic lens syndrome.

\section{DISCUSSION}

The studies reported in this review cover a wide range of countries and this must be considered in the formulation of any recommendations from the data. There is certainly a trend for intracapsular surgery to be supplanted by ECCE and PCIOL and more recently in the Indian subcontinent to be supplanted by MSICS. Even within the Indian subcontinent there is a marked difference between results of cataract camps and hospital based (Johnson 2000) treatments so when comparing results from different trials knowledge of the setting of the study is vital.

High volume surgery, which simply means surgical techniques with high patient throughput, is needed in the Indian subcontinent and Africa where cataract is common and resources are limited with almost three to six million blind from cataract (Dandona 1998; Foster 1991). However, any high volume procedure must also focus on quality. In a strive for the latter there is a trend for intracapsular cataract extraction (ICCE) to be replaced with ECCE with $\mathrm{PCIOL}$ implantation; the former technique is still being used in up to $40 \%$ of total surgeries in some developing countries (Gupta 1998). The three studies conducted in Asia (LAHAN; MIOLS; SACMS) are therefore relevant to the issue of the prevention of cataract blindness.

\section{Comparison of results of the three large studies in South Asia} There were important differences between these trials that need to be highlighted before interpreting the results. MIOLS was performed by a few surgeons in one centre of excellence using operating microscopes. The power of the lens required was calculated using biometry before surgery. The LAHAN study was conducted in a remote rural eye hospital in the Terai region of Nepal. No attempt was made to estimate the power of lens required before surgery. All surgery was done using $4.5 \mathrm{X}$ loupe magnification by two highly trained surgeons. The SACMS study was similar to LAHAN and was conducted in three centres, in India (Hyderabad), Bangladesh (Chittagong) and western Nepal and 19 surgeons undertook the operations. This study may well be more representative of usual surgical practice and ability, thereby having a greater external validity. The data in this review suggest that intracapsular extraction with a modern multiflex anterior chamber lens implant has similar safety and effectiveness as intracapsular extraction with aphakic glasses (AG) in the developing country setting. In the LAHAN and SACMS studies, the risk of a poor visual outcome (visual acuity less than 6/60) one to two years after surgery did not increase after implantation of an anterior chamber intraocular lens (ACIOL) compared to intracapsular extraction without implantation of an intraocular lens (IOL). At one year follow-up there were more people functionally blind 
in the intracapsular extraction with aphakic glasses (control) group due to the loss of aphakic spectacles. There were three cases of corneal decompensation identified 12 to 24 months after surgery in 2867 participants. Two of these cases occurred in the control group that is only one case of corneal decompensation occurred in a person with an ACIOL. Long term follow-up of up to five years after surgery did not show any increased risk of corneal decompensation. In the LAHAN study only, uveitis and secondary glaucoma occurred more frequently in eyes with an anterior chamber lens implant. Relatively high rates of uveitis were also seen in a non-randomised trial conducted in a black African population in southern Africa (Cook 1998). Higher rates of poor visual outcome were observed in SACMS where many surgeons in three different centres conducted the operations, however, these were still less than five per cent (visual acuity $6 / 60$ ) and there was no increased risk associated with implantation of anterior chamber lenses. In addition, corneal endothelial lens measurements in the SACMS study did not give cause for concern in contrast with previous studies with now outdated anterior chamber lenses (OCTET). Corneal decompensation was commonly seen with the first generations of anterior chamber lenses the first two to five years after implantation. Clinico-pathological data from developed country settings have shown no indication that the new generation of ACIOLs (Apple 2000) have given rise to a new epidemic of corneal complications.

\section{Comparison between intracapsular and extracapsular extraction.}

MIOLS, Vogel 1993 and Waddell 2004 were the only studies that compared two different surgical techniques. These studies showed that there were no clinically relevant differences in the visual acuity distributions of both BSCVA and UCVA between ECCE-PCIOL and ICCE-AG/ ACIOL. However, 155 patients lost their aphakic glasses at follow up; an obvious disadvantage. Overall there was no significant difference in complication incidence between the two techniques but the studies were not appropriately powered to detect differences, if the incidence of the complications is small. However, intracapsular extraction gave a significantly higher frequency of cystoid macular oedema (MIOLS) but this did not significantly increase the number of participants with severe vision loss $(<6 / 60)$. The documented secondary procedures by Waddell 2004 may be reduced by improved surgical technique in the ECCE group which would affect the overall results. All of the studies showed a significant increase of posterior capsular opacification (PCO) in the ECCE and PCIOL groups, $0.5 \%$ at one year and $13.5 \%$ after four years (random sub-sample). The longterm effect on vision will depend on the availability of Nd YAG laser posterior capsulotomy. Long-term complications of $\mathrm{ACIOL}$, for example stability in anterior chamber, glaucoma, corneal endothelial cell loss and the effect of training surgeons to perform the more complicated ECCE-PCIOL procedure were not addressed in these studies (Waddell 2004). Waddell 2004 was a paired eye study and was analysed by Wilcoxon matched pairs signed ranks test. Substantial improvements in vision-related quality of life were reported by people taking part in the MIOLS study. These improvements were more marked in people receiving an $\mathrm{IOL}$ compared to people receiving aphakic glasses.

\section{Comparison between phacoemulsification and extracapsular surgery}

The introduction of any new surgical technique requires validation against the previous gold standard to show an improvement in quality. There are nine trials that have compared these two techniques. They suggest a better UCVA following PHACO than ECCE . The majority of the trials showed no difference in best spectacle corrected visual acuity (BSCVA) between the two groups apart from Katsimpris 2004 which showed better vision in the PHACO group. However, this result may be due to the higher intraoperative complications and greater PCO in the ECCE group affecting vision. The complication rate both early and late was significantly lower in the PHACO group in all studies. Even though the endothelial cell loss was comparable between the two techniques there was a higher risk of severe loss in the PHACO group associated with removal of dense cataracts. The costs per procedure were not markedly different between the two techniques in a UK based study (MEHOX), however, a Malaysian study (Rizal 2003) showed ECCE to be significantly cheaper. The results of this study are limited by the fact the follow up was short and the ECCE group of participants still required a minimum of two further hospital visits for suture removal which was not accounted for in the costing. Extrapolation of these costs to other parts of the world where cataract surgery costs are very different must be made with caution.

Comparison between phacoemulsification and manual small incision cataract surgery

In an effort to combat the initial outlay of costs of PHACO, MSICS is an appealing alternative that may be performed in a high volume setting. Manual small incision cataract surgery offers an alterative to developing countries where there is a mixed population of hospital based and camp based cataract services. Two studies compared results of these two techniques, with PHACO having a significantly improved proportion of patients with uncorrected visual acuity (UCVA) $>=$ to $6 / 18(81.1 \% \vee 71 \%)$, there was no difference in BSCVA. There was no difference in the average postoperative astigmatism or surgical induced astigmatism between PHACO and MSICS but significantly less patients had $\angle 1 D$ astigmatism in the PHACO group $(P=0.04)$. There was no statistical difference in the number of patients who did not achieve functional vision in the operated eye, who had a poor visual outcome and surgical complications (including endothelial cell loss) between the two groups. There are few papers comparing costs of these two techniques as yet.

\section{Comparison between extracapsular extraction and manual small incision cataract surgery}

Studies comparing these two techniques have shown a significantly better UCVA $>=6 / 18$ and surgical induced astigmatism in the MSICS group (47.9\%) v ECCE group (37.3\%) RR $1.21(95 \% \mathrm{Cl}$ 1.06 to 1.37$)(P=0.0001)$, but no difference in BSCVA between the two groups.

There was no significant difference in complications or costs between the two groups. However, MSICS was advocated as procedure of choice due to equal costs and better unaided visual acuity results.

An observation from our meta-analyses is the heterogeneity of visual outcome data and follow up times amongst studies examining results following PHACO. This made statistical comparison between studies difficult and hence a uniform criteria for reporting the visual results from PHACO trials needs to be established. Firstly it is important that both UCVA and BCVA should be recorded. A decreased UCVA compared to best corrected visual acuity (BCVA) maybe due to surgically induced astigmatism, which 
has been found to be the case with MSICS (Venkatesh 2005). The difference between UCVA and BCVA often shows that residual refractive error is a major cause of poor visual outcome, just considering BCVA underestimates visual impairment. Therefore it would be useful to report UCVA and BCVA $>6 / 12$, especially in trials involving PHACO and MSICS in developing countries. This would give an estimate of the uncorrected refractive error (Dandona 2006) in patients following cataract surgery hence a further estimate of the overall cost to the patient. A suggestion would be for each study to report those patients with poor visual outcomes as those who did not achieve UCVA and BCVA of $6 / 60$ and who did not achieve UCVA and BCVA of $6 / 18$. They should also report good visual outcomes, as the number of patients with postoperative best corrected visual acuity of $6 / 12$ or better (Desai 1999). This level of vision is often used as the level of vision required for daily tasks (Congdon 2004). The World Health Organisation definitions of visual impairment are based only on distance visual acuity. There may be subsets of persons who have poor distance vision and good near vision or vice versa and these may impact on quality of life in different ways (Dandona 2006). Therefore, it would be useful to record near vision pre and postoperatively. The difference in the level of astigmatism when comparing the surgical techniques is particularly relevant in populations that have limited access to spectacles. It is clear that sutureless surgery produces less astigmatism and provides patients with faster visual recovery and fewer follow-up visits than surgery involving sutures.

It would also be easier to compare postoperative visual outcomes at standard time intervals. Although it is reasonable to compare $\mathrm{PHACO}$ and MSICS visual outcomes at six weeks it is not appropriate to compare these with techniques requiring sutures such as ECCE and ICCE which require a longer period for vision stabilisation due to suture induced astigmatism. A suggested standard time interval to record visual acuity would be six weeks, three months and one year postoperatively. It is recognised that long-term follow up is a challenge especially in developing countries.

Extracapsular cataract surgery is rapidly becoming more popular in developing countries and replacing ICCE. In India more than $50 \%$ of cataract surgeries are ECCE (Gupta 1998), yet there is little clinical data which compares intraoperative and long-term outcomes of extracapsular surgery conducted with sutures and sutureless surgery techniques (manual phacofragmentation or PHACO). Particular attention is required to assess the incidence of intraoperative complications (capsular rupture/ vitreous loss) and the long-term vision threatening complications including the frequency of PCO. Outcome studies have indicated that prospective follow up for at least three years would provide such information (Shrestha 2001).

Trials on comparative costing of surgical systems and procedures are needed to compare the cost benefit in intervention programmes for cataract blindness. Although there have been cost comparisons of PHACO and ECCE there has been few trials comparing the cost of MSICS. MEHOX (UK study) found PHACO and ECCE to have similar costs whereas the Malaysian study (Rizal 2003) found ECCE to be significantly cheaper, but this study did not include postoperative clinic visits. Other reports in the literature have documented higher providers costs for PHACO in comparison to ECCE (Asimakis 1996). Muralikrishnan 2004 looked at the economic cost of cataract surgery for PHACO, ECCE with IOL and MSICS in Southern India. The providers costs were highest for PHACO (US \$25.55) compared to MSICS (\$17.03) and ECCE (\$16.25), due to the need for expensive equipment and consumables for PHACO. The patients costs (direct and indirect) were highest for ECCE due to the increased number of days required for follow-up which incurs transportation and economic productivity loss. As a result MSICS was the lowest cost, whereas PHACO and ECCE had similar total costs (Muralikrishnan 2004). This study only reports on the cost of cataract surgical procedures, not on both costs and outcomes, which is what would be required for a cost-effectiveness study. The evidence suggests that MSICS which achieves similar visual outcome results to PHACO but is less expensive maybe the technique of choice. However further evaluation of the costeffectiveness of PHACO and MSICS is required prior to a change in policy. Cost is an important issue as it has proven to be one of the major barriers to the uptake of surgery by patients in developing countries, especially in Nigeria, Nepal (Yorston 2005) and Pakistan (Anjum 2006). Patients in most communities are willing to pay the equivalent of one month's wages for a cataract operation, therefore the cost of surgery should be based on the paying capacity of the population being treated.

There are also few comparative studies assessing the effect of different cataract extraction techniques on functioning vision and quality of life. Evaluation of cataract surgery outcomes should not be based on postoperative visual acuity alone It is important to show that the reduction in functional ability caused by cataract can be reversed by surgery (Mamidipudi 2003). It would be useful to evaluate quality of life, overall visual function and time taken to resume daily activities/ work following each of the surgical techniques. Solely considering visual outcomes does not give all the answers to which surgical technique is preferable for the patient, doctor or health care provider.

When assessing cataract surgical techniques outcome studies are also useful sources. For example, Venkatesh 2005 was an outcome study carried out at the same institute as MIOLS. In this case the outcome study had less favourable visual outcomes than the randomised controlled trial. This was thought to be the case because MIOLS had strict exclusion criteria and the outcome study did not exclude any patients with ocular co-morbidity. The outcome study was designed to demonstrate what happens on a routine basis rather than compare the effectiveness of procedures. Outcome studies are particularly useful for looking at adverse events such as postoperative endophthalmitis (Montan 2002; West 2005) and provide useful information for rare events but care must be taken when interpreting results to assess for bias.

\section{AUTHORS' CONCLUSIONS}

\section{Implications for practice}

This review provides evidence from nine randomised controlled trials that phacoemulsification (PHACO) gives a better visual outcome than extracapsular extraction with sutures. The majority of these trials have been conducted in developed countries in a specialised hospital setting. Comparative clinical data between manual small incision cataract surgery (MSICS), extracapsular extraction and phacoemulsification is only documented in a few studies but has shown the former technique to give better visual results than extracapsular cataract extraction (ECCE) and only slightly inferior to phacoemulsification in a developing world setting. When choosing the surgical procedure each patient should be examined on a case by case basis as each surgical technique has its limitations. The contraindications to MSICS include poor zonular 
integrity as a result of pseudoexfoliation, decompensated cornea and hard nuclear cataract (> grade IV).

Further work on cost / benefit of the introduction of sutureless surgery (manual phacofragmentation or PHACO) in programmes for the prevention of cataract blindness in the developing country setting is needed.

This review also found evidence that ECCE with a posterior chamber lens implant provides better visual outcome than intracapsular extraction with aphakic glasses or anterior chamber intraocular lens. This finding is based on the results of two trials. The data in the review also suggests that intracapsular extraction with an anterior chamber lens implant is an effective alternative to intracapsular extraction with aphakic glasses, with similar safety.

This review does not provide any evidence from controlled trials as to the rates of corneal complications with anterior chamber lenses more than seven or eight years after surgery. However, observational data from developed country settings do not indicate that this is likely to be a problem. Posterior capsular opacification in extracapsular extraction is common - the clinical implications in the developing world have not yet been fully documented.

No comparative data from developing regions outside India are available on the different surgical approaches and there are few published studies to give a basis for cost benefit analysis comparing the different surgical procedures.

Most young ophthalmologists in developing countries learn exclusively extracapsular techniques as this has been adopted as the primary surgery of choice. Technically MSICS is more difficult than a standard manual ECCE. Additional skills of hydro-dissection and hydro-delineation are required for MSICS but these are also useful for surgeons going on to learn PHACO. If these techniques are to be included in a cataract management programme it is important that ophthalmologists have received proper training in the techniques.

\section{Implications for research}

Considering the vast number of cataract surgical procedures performed worldwide there are few randomised controlled trials comparing different surgical techniques. Further data from developing regions are needed to compare all aspects of intraocular lens surgery with the four main surgical procedures - intracapsular extraction with an anterior chamber lens, extracapsular surgery with a posterior chamber lens with or without sutures, phacoemulsification and manual small incision cataract surgery. To make comparisons of the data between studies possible we propose setting a standard visual acuity recording system:
1. Uncorrected visual acuity (UCVA) and best corrected visual acuity (BCVA) worse than 6/60, UCVA and BCVA worse than 6/18 and UCVA and BCVA of better than 6/12.

2. Visual acuity recording postoperatively at six weeks and one year. (Six weeks post operatively is the time at which refraction is recommended as vision is thought to have stabilised).

3. Near vision to be recorded pre and postoperatively.

Further randomised controlled trials are required:

1. To compare ECCE with PCIOL and MSICS with PCIOL with longer term follow-up (preferably one, three and five years) to assess whether PCO occurs more frequently with either technique.

2. A larger study with at least one year follow up is required to compare PHACO and MSICS in terms of corneal endothelial cell loss (George 2005 is the only RCT that looks at this and is a small study with $\mathrm{N}=53$ ), and posterior capsular opacification. Other outcomes of interest are intraoperative complications, visual acuity and surgically induced astigmatism.

3. MSICS is performed by different techniques with variation in incision shape and site (superior or temporal), type of capsulotomy (continuous curvilinear, can opener or endocapsular) and use of viscoelastic or AC maintainer. A study of the optimal surgical technique comparing these variations is required.

4. To compare both the costs (providers and patients) and outcomes of PHACO, ECCE and MSICS techniques.

5. To assess the effect of the surgical techniques on quality of life.

6. To assess the effect of the surgical techniques on near vision as well as distance vision.

Techniques in cataract surgery are always changing but they are not usually subjected to trials, rather trial and error. It is important when considering trial design that a single surgeon performing both procedures does not produce a surgeon effect. This is bias introduced by a surgeon having more expertise in one intervention as compared to the other. To reduce bias the patient should be randomised to expert surgeons in each technique rather than having the same surgeon performing both procedures (Devereaux 2005). It is difficult for large scale randomised controlled trials (which take many years to execute, require long follow-up for rare but important outcomes and are expensive) to keep pace with the changing techniques and fashions but the evidence is needed before these changes are implemented.

\section{ACKNOWLEDGEMENTS}

The Cochrane Eyes and Vision Group editorial team developed and executed the electronic searches, especially Anupa Shah for her help and support. The World Health Organization for their support. We thank Catey Bunce, Jennifer Evans and Noela Prasad for their comments on earlier versions of this review. 


\section{RE F E R E N C E S}

\section{References to studies included in this review}

\section{Chee 1999 \{published data only\}}

Chee SP, Ti SE, Sivakumar M, Tan DT. Postoperative inflammation: extracapsular cataract extraction versus phacoemulsification. Journal of Cataract and Refractive Surgery 1999;25(9):1280-5.

\section{Dowler 2000 \{published data only\}}

Dowler JG, Hykin PG, Hamilton AM. Phacoemulsification versus extracapsular cataract extraction in patients with diabetes. Ophthalmology 2000;107(3):457-62.

\section{George 2005 \{published data only\}}

George R, Rupauliha P, Sripriya AV, Rajesh PS, Vahan PV, Praveen S. Comparison of endothelial cell loss and surgically induced astigmatism following conventional extracapsular cataract surgery, manual small-incision surgery and phacoemulsification. Ophthalmic Epidemiology 2005;12(5):293-7.

\section{Gogate 2005 \{published data only\}}

Gogate PM, Kulkarni SR, Krishnaiah S, Deshpande RD, Joshi SA, Palimkar A, et al. Safety and efficacy of phacoemulsification compared with manual small-incision cataract surgery by a randomized controlled clinical trial: six-week results. Ophthalmology 2005;112(5):869-74.

\section{Katsimpris 2004 \{published data only\}}

Katsimpris JM, Petropoulos IK, Apostolakis K, Feretis D. Comparing phacoemulsification and extracapsular cataract extraction in eyes with pseudoexfoliation syndrome, small pupil, and phacodonesis. Klinische Monatsblatter Fur Augenheilkunde 2004;221(5):328-33.

\section{LAHAN \{published and unpublished data\}}

Evans JR, Hennig A, Pradhan D, Foster A, Lagnado R, Poulson A, et al. Randomized controlled trial of anterior-chamber intraocular lenses in Nepal: long term follow-up. Bulletin of the World Health Organization 2000;78(3):372-8.

* Hennig A, Evans JR, Pradhan D, Johnson GJ, Pokhrel RP, Gregson R, et al. Randomised controlled trial of anterior chamber intraocular lenses. Lancet 1997;349(9059):1129-33.

Hennig A, Johnson GJ, Evans JR, Lagnado R, Poulson A, Pradhan $\mathrm{D}$, et al. Long term clinical outcome of a randomised controlled trial of anterior chamber lenses after high volume intracapsular cataract surgery. British Journal of Ophthalmology 2001;85(1):11-7.

Hennig A, Pradhan D, Evans JR, Johnson GJ, Foster A. Value of anterior chamber lenses in developing countries. Results of a clinical study [Stellenwert von Vorderkammerlinsen in Entwicklungslandern]. Ophthalmologe 1998;95(7):504-6.

Nag D, Hennig A, Foster A, Evans JR, Pradhan D, Johnson G, et al. Post-operative astigmatism after intracapsular cataract surgery: Results of a randomised controlled trial in Nepal. Indian Journal of Ophthalmology 2001;49:31-5.
Landau 1999 \{published data only\}

Landau IM, Laurell CG. Ultrasound biomicroscopy examination of intraocular lens haptic position after phacoemulsification with continuous curvilinear capsulorhexis and extracapsular cataract extraction with linear capsulotomy. Acta Ophthalmologica Scandinavica 1999;77(4):394-6.

\section{Laurell 1998 \{published data only\}}

Laurell CG, Zetterstrom C, Philipson B, Syren Nordqvist S. Randomized study of the blood-aqueous barrier reaction after phacoemulsification and extracapsular cataract extraction. Acta Ophthalmologica Scandinavica 1998;76(5):573-8.

\section{MEHOX \{published data only\}}

Bourne RR, Minassian D C, Dart JK, Rosen P, Kaushal S, Wingate N. Effect of cataract surgery on the corneal endothelium: modern phacoemulsification compared with extracapsular cataract surgery. Ophthalmology 2004;111(4):679-85.

Minassian DC, Rosen P, Dart JKG, Reidy A, Desai P, Sidhu M. Extracapsular cataract extraction compared with small incision surgery by phacoemulsification: a randomised trial. British Journal of Ophthalmology 2001;85(7):822-9.

MIOLS \{published data only\}

Fletcher A, Vijaykumar V, Selvaraj S, Thulasiraj RD, Ellwein LB. The Madurai Intraocular Lens Study. III: Visual functioning and quality of life outcomes. American Journal of Ophthalmology 1998;125(1):26-35

Natchiar GN, Thulasiraj RD, Negrel AD, Bangdiwala S, Rahmathallah R, Prajna NV, et al. The Madurai Intraocular Lens Study. I: A randomized clinical trial comparing complications and vision outcomes of intracapsular cataract extraction and extracapsular cataract extraction with posterior chamber intraocular lens. American Journal of Ophthalmology 1998;125(1):1-13

* Prajna NV, Chandrakanath KS, Kim R, Narendran V, Selvakumar S, Rohini G, et al. The Madurai Intraocular Lens Study. II: Clinical outcomes. American Journal of Ophthalmology 1998;125(1):14-25

Prajna NV, Ellwein LB, Selvaraj S, Marajula K, Kupfer C. The Madurai Intraocular Lens Study. IV: Posterior capsular opacification. American Journal of Ophthalmology 2000;130(3):304-9.

\section{OCTET \{published data only\}}

* Oxford Cataract Treatment and Evaluation Team. Cataract surgery: interim results and complications of a randomised controlled trial. British Journal of Ophthalmology 1986;70(6):402-10.

Oxford Cataract Treatment and Evaluation Team. Long-term corneal endothelial cell loss after cataract surgery. Archives of Ophthalmology 1986;104(8):1170-5. 
Oxford Cataract Treatment and Evaluation Team. Use of grading system in the evaluation of complications in a randomised controlled trial on cataract surgery. British Journal of Ophthalmology 1986;70(6):411-4.

PUNE \{published data only\}

Gogate PM, Deshpande M, Wormald RP. Is manual small incision cataract surgery affordable in the developing countries? A cost comparison with extracapsular cataract extraction. British Journal of Ophthalmology 2003;87(7):843-6.

* Gogate PM, Deshpande M, Wormald RP, Deshpande R, Kulkarni SR. Extracapsular cataract surgery compared with manual small incision cataract surgery in community eye care setting in western India: a randomised controlled trial.. British Journal of Ophthalmology 2003;87(6):667-72.

\section{Ravalico 1997 \{published data only\}}

Ravalico G, Tognetto D, Palomba MA, Lovisato A, Baccara F. Corneal endothelial function after extracapsular cataract extraction and phacoemulsification. Journal of Cataract and Refractive Surgery 1997;23(7):1000-5.

\section{Rizal 2003 \{published data only\}}

Rizal AM, Aljunid SM, Normalina M, Hanom AF, Chuah KL, Suzainah $\mathrm{Y}$, et al. Cost analysis of cataract surgery with intraocular lens implantation: a single blind randomised clinical trial comparing extracapsular cataract extraction and phacoemulsification. Medical Journal of Malaysia 2003;58(3):380-6.

\section{SACMS \{published data only\}}

* Snellingen T, Shrestha KJ, Huq F, Husain R, Koirala S, Gullapalli RN, et al. The South Asian Cataract Management Study: Complications, vision outcomes and corneal endothelium cell loss in a randomised multicenter clinical trial comparing intracapsular cataract extraction with and without anterior chamber intraocular lens implantation. Ophthalmology 2000;107:231-40.

The South Asian Cataract Management Study Group. The South Asian Cataract Management Study. I. The first 662 cataract surgeries: a preliminary report. British Journal of Ophthalmology 1995;79(11):1029-35.

\section{Vogel 1993 \{published data only\}}

Vogel M, Behrens-Baumann W, Petersen J, Quentin C-D, Hilgers R, Kron R, et al. Comparison of rate of complications after intracapsular and extracapsular cataract extraction with lens implantation. Results of a prospective, randomized, clinical study [Vergleich der Komplicationen nach intra- und extrakapsularer Kataraktextraktion mit Linsenimplantation. Ergebnisse einer prospektiven, randomisierten, klinischen Studie.]. Klinische Monatsblatter fur Augenheilkunde 1993;203:43-52.

\section{Waddell 2004 \{published data only\}}

Waddell KM, Reeves BC, Johnson GJ. A comparison of anterior and posterior chamber lenses after cataract extraction in rural Africa: a within patient randomised trial. British Journal of Ophthalmology 2004;88(6):734-9.

\section{References to studies excluded from this review}

Alpar 1984 \{published data only\}

Alpar JJ. Cataract extraction and diabetic retinopathy. Journal of the American Intra-ocular Implant Society 1984;10:433-7.

Bomer 1995 \{published data only\}

Bomer TG, Lagreze WD, Funk J. Increased intraocular pressure after cataract extraction--effect of surgical technique, surgical procedure and preventive drug administration. A prospective, randomized double-blind study. Klinische Monatsblatter Fur Augenheilkunde 1995;206(1):13-9.

Bourne 2003 \{published data only\}

Bourne RR, Dineen BP, Ali SM, Huq DM, Johnson GJ. Outcomes of cataract surgery in Bangladesh: results from a population based nationwide survey. British Journal of Ophthalmology 2003;87(7):813-9.

\section{De Laage 1988 \{published data only\}}

Laage de P, Deidier D. Comparative study of intracapsular cataract extraction with anterior chamber lens implant and extracapsular cataract extraction with posterior chamber lens implant [Etude comparative de l'extraction intra-capsulaire avec implant de chambre anterieure et de l'extraction extracapsulaire avec implant de chambre posterieure]. Ophthalmologie 1988;2(3):235-8.

\section{Ford 2005 \{published data only\}}

Ford DT, Whiston JT. The Effect of uncomplicated cataract surgery on intraocular prssure. Clinical \& Surgical Ophthalmology 2005;23(1):10-16.

Hsu 2005 \{published data only\}

Hsu SY, Wu WC. Comparison of phacoemulsification and planned extracapsular cataract extraction in combined pars plana vitrectomy and posterior chamber intraocular lens implantation. Ophthalmic Surgery, Lasers \& Imaging 2005;36(2):108-13.

\section{Jurgens 1997 \{published data only\}}

Jurgens I, Matheu A, Castilla M. Ocular hypertension after cataract surgery: a comparison of three surgical techniques and two viscoelastics. Ophthalmic Surgery and Lasers 1997;28(1):30-6.

\section{Leen 1993 \{published data only\}}

Leen MM, Ho CC, Yanoff M. Association between surgicallyinduced astigmatism and cataract incision size in the early postoperative period. Ophthalmic Surgery 1993;24(9):586-92.

\section{Loo 2004 \{published data only\}}

Loo CY, Kandish M, Arumugam G, Goh PP, John EE, Gurusami B, Kumar TV, Karunakar TV, Azmi S, Lim TO. Cost efficiency and cost effectiveness of cataract surgery at the Malaysian Ministry of Health ophthalmic services. International Ophthalmology 2004;25(2):81-7. 
Noske 1988 \{published data only\}

Noske W, Pahlitzsch T, Kirchner J. Postoperative behavior of the intraocular pressure in risk patients following phacoemulsification and extracapsular cataract extraction--a double-blind study of the effect of acetazolamide. Fortschritte Der Ophthalmologie 1988;85(5):492-4.

\section{Quentin 1993 \{published data only\}}

Quentin CD, Behrens-Baumann W, Lindemann K, Hilgers R, Vogel M. Cystoid macular edema and visual acuity with intracapsular cataract extraction and Choyce anterior chamber lens vs. extracapsular cataract extraction and posterior chamber lens in the partner eye [Zystoides makulaodem und sehscharfe bei ICCE und Choyce-VKL vs. ECCE und HKL am partnerauge]. Ophthalmologe 1993;90(4):364-6.

\section{Ruellan 1994 \{published data only\}}

Ruellan YM, Fu WL, Hamard H, Auclin F, Ullern M. Corneal endothelium, extracapsular cataract extraction and phacoemulsification. Ophtalmologie 1994;8(2):169-70.

\section{References to studies awaiting assessment}

Guo 2005 \{published data only\}

Guo QX, He W, Che XL. Analysis of difference of visual recovery after cataract extraction in aged people. Zhongguo Linchuang Kangfu 2005;9(26):40-1.

\section{Liang 2006 \{published data only\}}

Liang YC, Huang B H, Xie X. Clinical comparison of sutureless small incision extracapsular cataract extraction and modern extracapsular cataract extraction. International Journal of Ophthalmology 2006;6(2):470-2.

\section{Parmar 2006 \{published data only\}}

Parmar P, Salman A, Kaliamurthy J, Prasanth DA, Thomas PA, Jesudasan CA. Anterior chamber contamination during phacoemulsification and manual small-incision cataract surgery. American Journal of Ophthalmology 2006;141(6):1160-1.

\section{Additional references}

\section{Anjum 2006}

Anjum KM, Qureshi MB, Khan MA, Jan N, Ali A, Ahmad K, et al. Cataract blindness and visual outcome of cataract surgery in a tribal area in Pakistan. British Journal of Ophthalmology 2006;90:135-8

\section{Apple 1989}

Apple DH, Mamalis N, Olson RJ, Kincaid MC. Intraocular lenses: Evolution, Designs, Complications, and Pathology. Williams \& Wilkins, 1989:225-361.

\section{Apple 1992}

Apple DJ, Solomon KD, Tetz MR, Assia El, Holland EY, Legler UFC, et al. Posterior capsule opacification. Survey of Ophthalmology 1992;37(2):73-116.

\section{Apple 2000}

Apple DJ, Ram J, Foster A, Peng Q. Elimination of cataract blindness: a global perspective entering the new millenium. Survey of Ophthalmology 2000;45(Supplement 1):S1-196.

\section{Asimakis 1996}

Asimakis P, Coster DJ, Lewis DJ. Cost effectiveness of cataract surgery-A comparison of conventional extra capsular surgery and phacoemulsification at Flinders Medical Centre. Australia and New Zealand Journal of Ophthalmology 1996;24:319-25.

\section{Blumenthal 1992}

Blumenthal M, Ashkenazi I, Assia E, Cahane M. Small-incision manual extracapsular cataract extraction using selective hydrodissection. Ophthalmic Surgery 1992;23:699-701.

\section{Blumenthal 1994}

Blumenthal M. Manual ECCE, the present state of the art. Klinische Monatsblatter fur Augenheilkunde 1994;205:266-70.

\section{Congdon 2004}

Congdon N, O'Colmain B, Klaver CC, Klein R, Munoz B, Friedman DS, et al. Causes and prevalence of visual impairment among adults in the United States. Archives of Ophthalmology 2004;122:477-85

\section{Cook 1998}

Cook CD, Evans JR, Johnson GJ. Is anterior chamber lens implantation after intracapsular cataract extraction safe in rural black patients in Africa? A pilot study in KwaZulu-Natal, South Africa. Eye 1998;12(5):821-5.

\section{Dandona 1998}

Dandona L, Dandona R, Naduvilath TJ, McCarty CA, Nanda A, Srinivas $\mathrm{M}$, et al. Is current eye-care-policy focus almost exclusively on cataract adequate to deal with blindness in India?. Lancet 1998;351(9112):1312-6.

\section{Dandona 2006}

Dandona L, Dandona R. Revision of visual impairment definitions in the International Statitical Classification of Diseases. BMC Medicine 2006;4:1-7.

\section{Desai 1999}

Desai P, Minassian DC, Reidy A. National cataract surgery survey 1997-8: a report of the results of the clinical outcomes. British Journal of Ophthalmology 1999;83(12):1336-40.

\section{Devereaux 2005}

Devereaux PJ, Bhandari M, Clarke M, Montori VM, Cook DJ, Yusuf $S$, et al. Need for expertise based randomised controlled trials. BMJ 2005;330:88-92.

\section{Duane 1986}

Duane T. Textbook of Ophthalmology. Lippincott-Raven, 1986:25.

\section{Elder 1969}

Duke-Elder S. Systems of Ophthalmology. XI Diseases of the lens. Vol. 11, Henry Kimpton, 1969. 


\section{Fletcher 1999}

Fletcher A, Donoghue M, Devavaram J, Thulsiraj RD, Scott S, Abdalla M, et al. Low uptake of eye services in rural India: a challenge for programs of blindness prevention. Archives of Ophthalmology 1999;117(10):1393-9.

\section{Foster 1991}

Foster A. Who will operate on Africa's 3 million curably blind people?. Lancet 1991;337(8752):1267-9.

\section{Foster 2001}

Foster A. Cataract and "Vision 2020-the right to sight" initiative. British Journal of Ophthalmology 2001;85:635-7.

\section{Gupta 1998}

Gupta AK, Tewari HK, Ellwein LB. Cataract surgery in India: Results of a 1995 survey of ophthalmologists. Indian Journal of Ophthalmology 1998;46:47-50.

\section{Hennig 1999}

Hennig A. Tunnel sutureless high volume cataract surgery. IAPB 6th General Assembly. Beijing, September 61999.

\section{Higgins 2005a}

Higgins JPT, Green S, editors. Cochrane Handbook for Systematic Reviews of Interventions 4.2.5 [updated May 2005] In: The Cochrane Library, Issue 3, 2005. Chichester, UK: John Wiley \& Sons, Ltd.

\section{Higgins 2005b}

Higgins JPT, Green S, editors. Assessment of study quality. Cochrane Handbook for Systematic Reviews of Interventions 4.2.5 [updated May 2005; Section 6]. In: The Cochrane Library, Issue 3, 2005. Chichester, UK: John Wiley \& Sons, Ltd.

\section{Javitt 1992}

Javitt JC, Tielch JM, Canner JK, Kolb MM, Sommer A, Steinberg EP. National outcomes of cataract extraction. Increased risk of retinal complications associated with Nd:YAG laser caposulotomy. The Cataract Patient Outcomes Research Team. Ophthalmology 1992;99(10):1487-98.

\section{Johnson 2000}

Johnson GJ. Improving outcome of cataract surgery in developing countries. Lancet 2000;355(9199):158-9.

\section{Kupfer 1994}

Kupfer C. The International Agency for the Prevention of Blindness. American Journal of Ophthalmology 1994;117(2):253-7.

\section{Limburg 1996}

Limburg H, Kumar R, Bachani D. Monitoring and evaluating cataract intervention in India. British Journal of Ophthalmology 1996;80(11):951-5.

\section{Mamidipudi 2003}

Mamidipudi PR, Vasavada AR, Merchant SV, Namboodiri VN, Ravilla TD. Quality of life and visual function assessment after phacoemulsification in and urban Indian population. Journal of Cataract and Refractive Surgery 2003;29:1143-51.

\section{Mehta 1999}

Mehta KR, Mehta CK. Teaching standards in phacoemulsification. How realistic are they?. Symposium on Phacoemulsification. VI Ophthalmological Congress of SAARC Countries. Kathmandu, November 201999.

\section{Minassian 1990}

Minassian DC, Mehra V. 3.8 Million blinded by cataract each year: projections from the first epidemiological study of the incidence of cataract blindness in India. British Journal of Ophthalmology 1990;74(6):341-3.

\section{Montan 2002}

Montan P, Lundstrom M, Stenevi U, Thorburn W. Endophthalmitis following cataract surgery in Sweden. The 1998 national prospective survey. Acta Ophthalmalogica Scandinavica 2002;80:258-61.

\section{Muralikrishnan 2004}

Muralikrishnan R, Venkatesh R, Prajna NV, Frick KD. Economic cost of cataract surgery procedures in an established eye care centre in Southern India. Ophthalmic Epidemiology 2004;11(5):369-80.

\section{Norregaard 1999}

Norregaard JC, Bernth-Pettersen P, Bellan L, Alonso J, Black C, Dunn $E$, et al. Intraoperative clinical practice and risk of early complications after cataract extraction in the Unites States, Canada, Denmark and Spain. Ophthalmology 1999;106(1):42-8.

\section{Passolini 2004}

Passolini D, Mariotti SP, Pokharel GP, Pararajasegarm R, Etyalale D, Negrel AD, et al. 2002 global update of available data on visual impairment:a compilation of population-based prevalence studies. Ophthalmic Epidemiology 2004;11:67-115.

\section{Resnikoff 2004}

Resnikoff S, Passolini D, Etyalale D, Kocur I, Pararajasegarm R, Pokharel GP, et al. Global data on visual impairment in the year 2002. Bulletin of The World Health Organisation 2004;82:844-51.

\section{Ruit 2000}

Ruit S, Paudyal G, Gurung R, Tabin G, Moran D, Brian G. An innovation in developing world cataract surgery: sutureless extracapsular cataract extraction with intraocular lens implantation. Clinial and Experimental Ophthalmology 2000;28:274-9.

\section{Shrestha 2001}

Shrestha JK, Pradhan YM, Snellingen T. Outcomes of extracapsular surgery in eye camps of eastern Nepal. British Journal of Ophthalmology 2001;85:648-52.

\section{Snellingen 1998}

Snellingen T, Shreshta BR, Gharti MP, Shrestha JK, Upadhyay MP, Pokhrel RP. Socioeconomic barriers to cataract surgery in Nepal: the South Asian Cataract Management Study. British Journal of Ophthalmology 1998;82(12):1424-8. 


\section{Thylefors 1998}

Thylefors B. A global initiative for the elimination of avoidable blindness. American Journal of Ophthalmology 1998;125(1):90-3.

\section{Vaidyanathan 1999}

Vaidyanathan K, Limburg H, Foster A, Pandey RM. Changing trends in barriers to cataract surgery in India. Bulletin of the World Health Organization 1999;77(2):104-9.

\section{Venkatesh 2005}

Venkatesh R, Muralikrishnan, Balent LC, Prakash SK, Prajna NV. Outcomes of high volume cataract surgeries in a developing country. British Journal of Ophthalmology 2005;89:1079-83.

\section{West 2005}

West E, Behrens A, McDonnell PJ, Tielsch JM, Schein OD. The Incidence of endophthalmitis after cataract surgery among the US Medicare population Increased between 1994 and 2001. Ophthalmlogy 2005;112:1388-94.

\section{WHO 2005}

World Health Organization Executive Board. Prevention of Avoidable Blindness and Visual Impairment. Executive Board 117th session, EB117/35 22 December 2005.

\section{Yorston 2005}

Yorston D. High-volume surgery in developing countries. Eye 2005;19:1083-9.

* Indicates the major publication for the study

\section{CHARACTERISTICS OF STUDIES}

Characteristics of included studies [ordered by study ID]

Chee 1999

$\begin{array}{ll}\text { Methods } & \text { Randomised controlled trial } \\ & \text { Masking of outcome assessment: patient - yes; assessor - post op observer was masked to surgical pro- } \\ & \text { cedure (suture techniques different) }\end{array}$
cedure (suture techniques different)

$\begin{array}{ll}\text { Participants } & \text { Number randomised: } 34 \text { patients } \\ \text { Age: mean } 63.06 \text { years } \\ \text { Inclusion criteria: age-related cataract } \\ \text { Exclusion criteria: diabetics } \\ \text { Country: Singapore }\end{array}$

\begin{tabular}{|c|c|}
\hline Interventions & $\begin{array}{l}\text { Phaco versus ECCE } \\
\text { Maximum follow-up: } 3 \text { months (VA recorded at } 2 \text { months) }\end{array}$ \\
\hline Outcomes & Postoperative inflammation - laser flare meter/ slit lamp; VA \\
\hline Notes & 2 surgeons \\
\hline Risk of bias & \\
\hline Bias & Authors' judgement Support for judgement \\
\hline Allocation concealment? & Unclear risk \\
\hline
\end{tabular}

\section{Dowler 2000}

\begin{tabular}{ll}
\hline Methods & $\begin{array}{l}\text { Randomised controlled trial } \\
\text { Paired study: one type of surgery in each eye } \\
\text { Masking of outcome assessment: not reported. PHACO: suture less; ECCE: } 5 \text { sutures }\end{array}$ \\
\hline Participants & Number randomised: 46 patients \\
& $\begin{array}{l}\text { Age: Mean } 66 \text { ( } 45 \text { to } 81) \text { years } \\
\text { Inclusion criteria: diabetic patients; cataract sufficient to cause visual symptoms or impede fundus vi- } \\
\text { sualisation in both eyes }\end{array}$
\end{tabular}


Dowler 2000 (Continued)

Exclusion criteria: clinically significant macular oedema at time of surgery; high risk proliferative retinopathy at time of surgery; amblyopia; intercurrent ocular disease; history of prior ocular surgery Country: UK

\begin{tabular}{ll}
\hline Interventions & $\begin{array}{l}\text { Phaco versus ECCE } \\
\text { Follow-up: } 26 \text { months (range } 15 \text { to } 37)\end{array}$ \\
\hline Outcomes & VA; anterior segment inflammation; capsulotomy; incidence of CSME; retinopathy progression \\
\hline Notes & $\begin{array}{l}\text { Sample size too small to detect a significant difference in the incidence of CSME or progression of } \\
\text { retinopathy between the two groups }\end{array}$
\end{tabular}

\section{Risk of bias}

\begin{tabular}{lll}
\hline Bias & Authors' judgement & Support for judgement \\
\hline Allocation concealment? & Unclear risk & B - Unclear \\
\hline
\end{tabular}

\section{George 2005}

$\begin{array}{ll}\text { Methods } & \text { Randomised controlled trial } \\ & \text { Masking of outcome assessment: not reported. ECCE: sutured; PHACO \& MSICS: not routinely sutured } \\ & \text { unless wound leak }\end{array}$
unless wound leak

\begin{tabular}{ll}
\hline Participants & $\begin{array}{l}\text { Number randomised: } 186 \text { patients } \\
\text { Age: Mean 58.74 years } \\
\text { Inclusion criteria: patient undergoing planned cataract surgery; otherwise normal pre-op examination; } \\
\text { cataract < grade III } \\
\text { Exclusion criteria: other potential causes of decreased vision; complicated cataracts; non age-related } \\
\text { cataracts; phacodenesis; glaucoma or retinal pathology } \\
\text { Country: India }\end{array}$ \\
\hline Interventions & $\begin{array}{l}\text { PHACO versus ECCE versus MSICS } \\
\text { Follow-up: } 6 \text { weeks }\end{array}$ \\
\hline Outcomes & SIA; EC - specular microscopy counts; VA \\
\hline Notes & 2 surgeons \\
PHACO - 5 mm incision rigid lens \\
MSICS - Blumenthal technique
\end{tabular}

Gogate 2005

Methods Randomised controlled trial

Masking of outcome assessment: patient - yes; before, during and after surgery; assessor - yes.Post op evaluation done by ophthalmologist who was not a participating surgeon and was masked as to the treatment allocation code. Assessor may be able to determine the type of surgery involved as the IOL in 
PHACO was foldable and in MSICS was PMMA. Location and size of suture (suture technique not reported)

\begin{tabular}{ll}
\hline Participants & Number randomised: 400 patients \\
& Age: 40 to 90 years (mean 61.25 years) \\
Inclusion criteria: patients with cataract attending 20 July 2002 to 28 December 2003 & $\begin{array}{l}\text { Exclusion criteria: require combined surgical procedure; eye disorders that may compromise vision } \\
\text { (eg. amblyopia, glaucoma, diabetic retinopathy, macular degeneration); high myopes (axial length > } \\
\text { 26.5mm); age <40 or >90; mobility thought to hinder follow-up; unable to give informed consent } \\
\text { Country: Pune, India }\end{array}$ \\
\hline Interventions & $\begin{array}{l}\text { Phaco versus MSICS } \\
\text { Follow-up: } 6 \text { weeks }\end{array}$ \\
\hline Outcomes & VA; astigmatism; complications \\
\hline Notes & PHACO: Hydrophilic acrylic \\
& ECCE: PMMA Currently studying results of 1 year follow-up \\
\hline Risk of bias & Authors' judgement Support for judgement \\
\hline Bias & Low risk A - Adequate \\
\hline Allocation concealment?
\end{tabular}

Katsimpris 2004

$\begin{array}{ll}\text { Methods } & \text { Randomised controlled trial } \\ & \text { Masking of outcome assessment: not reported. PHACO: } 1 \text { suture; ECCE: } 4 \text { to } 5 \text { sutures. Same IOL used } \\ & \text { for both techniques }\end{array}$

\begin{tabular}{ll}
\hline Participants & $\begin{array}{l}\text { Number randomised: } 94 \text { patients } \\
\text { Age: mean 76.3 years } \\
\text { Inclusion criteria: patients with cataract in association with pseudoexfoliation; small pupil; small to } \\
\text { moderate phacodenesis } \\
\text { Exclusion criteria: partial or complete subluxation; vitreous present in anterior chamber } \\
\text { Country: Greece }\end{array}$ \\
\hline Interventions & $\begin{array}{l}\text { Phaco versus ECCE } \\
\text { Follow-up: Mean } 14 \pm 6.2 \text { months }\end{array}$ \\
\hline Outcomes & Intraoperative complications; VA; PCO; IOL decentration; corneal oedema \\
\hline Notes & 1 surgeon \\
\hline Risk of bias & Authors' judgement Support for judgement \\
\hline Bias & Unclear risk $\quad$ B - Unclear \\
\hline Allocation concealment?
\end{tabular}


LAHAN

\begin{tabular}{ll}
\hline Methods & $\begin{array}{l}\text { Randomised controlled trial } \\
\text { Masking of outcome assessment: patient and assessor - no. Obvious difference of one group wearing } \\
\text { aphakic glasses }\end{array}$ \\
\hline Participants & $\begin{array}{l}\text { Number randomised: } 2,000 \text { patients } \\
\text { Age: } 40 \text { to } 64 \text { years (mean } 55 \text { years) } \\
\text { Inclusion criteria: bilateral cataract; VA 6/36 or worse in both eyes; live close by } \\
\text { Exclusion criteria: known pre-existing ocular disease; hypertension; diabetes } \\
\text { Country: Terai region, Nepal. }\end{array}$ \\
\hline Interventions & ICCE/AG versus ICCE/ACIOL \\
\hline Follow-up: five years \\
\hline Notes blinding complication rate; causes of severe visual impairment \\
\hline Risk of bias & ACIOL: single-piece four-point fixation CILCO Kelman Multiflex III lens (Alcon) \\
\hline Bias & Authors' judgement Support for judgement \\
\hline Allocation concealment? & Low risk \\
\hline
\end{tabular}

Landau 1999

\begin{tabular}{ll}
\hline Methods & $\begin{array}{l}\text { Randomised controlled trial } \\
\text { Masking of outcome assessment: patient and assessor - yes. UBM was performed by ophthalmogist } \\
\text { who was unaware of the surgical technique }\end{array}$ \\
\hline Participants & $\begin{array}{l}\text { Number randomised: } 42 \text { patients } \\
\text { Age: mean } 74.25 \text { (68 to } 82 \text { ) years } \\
\text { Inclusion criteria: patients with cataract } \\
\text { Exclusion criteria: no other ocular disease } \\
\text { Country: Sweden }\end{array}$ \\
\hline Interventions & $\begin{array}{l}\text { Phaco versus ECCE } \\
\text { Follow-up: mean } 24 \text { months (range 18 to 30) }\end{array}$ \\
\hline Outcomes & UBM - IOL haptic position; AC depth \\
\hline Notes & 1 surgeon
\end{tabular}

\section{Risk of bias}

\begin{tabular}{lll}
\hline Bias & Authors' judgement & Support for judgement \\
\hline Allocation concealment? & Low risk & A - Adequate \\
\hline
\end{tabular}

\section{Laurell 1998}

$\begin{array}{ll}\text { Methods } & \text { Randomised controlled trial } \\ & \text { Masking of outcome assessment: patient and assessor - yes. Performed by a nurse and ophthalmolo- } \\ & \text { gist without knowledge of surgical technique }\end{array}$


Laurell 1998 (Continued)
Participants
Number randomised: 186 patients
Age: Mean 58.74 years
Inclusion criteria: patients enrolled for cataract surgery; age $>64$
Exclusion criteria: pseudoexfoliation syndrome; small pupils (<5mm post dilatation); glaucoma;
uveitis; dark brown irides; diabetes; treatment with eye drops or anti-inflammatory drugs
Country: Sweden

\begin{tabular}{ll} 
Interventions & $\begin{array}{l}\text { Phaco versus ECCE } \\
\text { Follow-up: } 3 \text { months }\end{array}$ \\
\hline Outcomes & Fluorophotometry; laser flare photometry; VA; pachymetry \\
\hline Notes & $\begin{array}{l}1 \text { surgeon } \\
\text { Blue iridies only }\end{array}$
\end{tabular}

\section{Risk of bias}

\begin{tabular}{lll}
\hline Bias & Authors' judgement & Support for judgement \\
\hline Allocation concealment? & Low risk & A - Adequate \\
\hline
\end{tabular}

\section{MEHOX}

\begin{tabular}{ll}
\hline Methods & Randomised controlled trial \\
& $(2$ centre) \\
& Masking of outcome assessment: patient and assessor - yes. Performed by an optometrist
\end{tabular}

Number randomised: 500 patients
Age: $40+$ (mean 72 years)
Inclusion criteria: consenting patient; age-related cataract; resident in the region; willing and able to
attend regular follow up
Exclusion criteria: hard, highly brunescent cataracts; eye disorders that may compromise vision (eg.
amblyopia, glaucoma, diabetic retinopathy, macular degeneration); high myopes (axial length $>26.5$
mm)
Country: UK

\begin{tabular}{ll}
\hline Interventions & Phacoemulsification versus ECCE \\
& Follow-up: 1 year
\end{tabular}

Outcomes VA; astigmatism; capsule rupture/vitreous loss; capsule opacity; endothelial cell loss

\section{Notes}

\section{Risk of bias}

\begin{tabular}{lll}
\hline Bias & Authors' judgement & Support for judgement \\
\hline Allocation concealment? & Low risk & A - Adequate \\
\hline
\end{tabular}

MIOLS

Methods Randomised controlled trial


MIOLS (Continued)

Masking of outcome assessment: patient and assessor - no. Obvious difference of treatment group wearing aphakic glasses

Pumber randomised: 3,400 patients
Age: 40 to 70 years (mean 59 years)
Inclusion criteria: age 40 to 75 ; bilateral blindness caused by age-related cataract; VA 6/36 or worse in
better eye; within $150 \mathrm{~km}$
Exclusion criteria: diabetics; hypertensive; patients who insisted on IOL; existence of ocular pathology;
non-ocular reasons - refused to participate; If preference to undergo either of the 2 procedures
Country: Madurai, south India

Interventions ICCE/AG versus ECCE/PCIOL

Follow-up: > 1 year

\begin{tabular}{ll}
\hline Outcomes & VA; complications (OCTET grades); quality of life \\
\hline Notes & PCIOL: standard three-piece plano convex (Aurolab)
\end{tabular}

\section{Risk of bias}

\begin{tabular}{lll}
\hline Bias & Authors' judgement & Support for judgement \\
\hline Allocation concealment? & Low risk & A - Adequate \\
\hline
\end{tabular}

\section{OCTET}

\begin{tabular}{|c|c|c|}
\hline Methods & \multicolumn{2}{|c|}{$\begin{array}{l}\text { Randomised controlled trial } \\
\text { Masking of outcome assessment: patient - no. Masked procedures reported for endothelial cell count, } \\
\text { reading fluorescein angiograms and refraction. Clinical assessment was not masked as obvious differ- } \\
\text { ence of one treatment group wearing contact lens/ different IOL types }\end{array}$} \\
\hline Participants & \multicolumn{2}{|c|}{$\begin{array}{l}\text { Number randomised: } 331 \text { patients } \\
\text { Age: } 55 \text { to } 90 \text { years } \\
\text { Inclusion criteria: age } 55 \text { to } 90 \text {; uncomplicated senile cataract; patient willing to wear a contact lens } \\
\text { Exclusion criteria: any patient with other ocular disease likely to affect visual outcome } \\
\text { Country: UK }\end{array}$} \\
\hline Interventions & \multicolumn{2}{|c|}{$\begin{array}{l}\text { ICCE/contact lens versus ICCE/iris supported versus ECCE/iridocapsular lens } \\
\text { Follow-up: } 4 \text { years }\end{array}$} \\
\hline Outcomes & \multicolumn{2}{|c|}{$\begin{array}{l}\text { VA; complications (OCTET grades); corneal endothelial cell loss (corneal endothelial cells were pho- } \\
\text { tographed using a non-contact specular microscope; cell density was assessed by grid counting) }\end{array}$} \\
\hline Notes & \multicolumn{2}{|c|}{$\begin{array}{l}\text { Iris supported lens: 4-loop iris supported Federov lens } \\
\text { Iridocapsular lens: 2-loop Binkhort iridocapsular lens }\end{array}$} \\
\hline \multicolumn{3}{|l|}{ Risk of bias } \\
\hline Bias & Authors' judgement & Support for judgement \\
\hline Allocation concealment? & Unclear risk & B - Unclear \\
\hline
\end{tabular}




\begin{tabular}{|c|c|}
\hline Methods & $\begin{array}{l}\text { Randomised controlled trial } \\
\text { Masking of outcome assessment: patient - yes. Doctors (not participating surgeon) and optometrists } \\
\text { were assessors. Not told about the type of surgery done. Obviously unable to mask sutures, size and lo- } \\
\text { cation of incision }\end{array}$ \\
\hline Participants & $\begin{array}{l}\text { Number randomised: } 741 \text { patients } \\
\text { Age: } 40 \text { to } 90 \text { years (mean } 64.18 \text { years) } \\
\text { Inclusion criteria: presented with cataract } 7 \text { April } 2001 \text { to } 17 \text { May 2001; age } 40 \text { to } 90 \\
\text { Exclusion criteria: patient preference to one treatment; ocular co morbidity capable of compromis- } \\
\text { ing vision; requirement for combined surgical procedure; axial length > } 26 \text { mm; refused to consent for } \\
\text { study } \\
\text { Country: Pune, India }\end{array}$ \\
\hline Interventions & $\begin{array}{l}\text { ECCE versus MSICS } \\
\text { Follow-up: } 6 \text { weeks }\end{array}$ \\
\hline Outcomes & VA; complications (OCTET); cost \\
\hline Notes & 8 surgeons \\
\hline
\end{tabular}

\section{Risk of bias}

\begin{tabular}{lll}
\hline Bias & Authors' judgement & Support for judgement \\
\hline Allocation concealment? & Low risk & A-Adequate \\
\hline
\end{tabular}

Ravalico 1997

$\begin{array}{ll}\text { Methods } & \text { Randomised controlled trial } \\ & \text { Masking of outcome assessment: not reported. PHACO: running cross suture, } 3.2 \text { mm incision; ECCE: } \\ & \text { running cross suture, } 10 \mathrm{~mm} \text { incision }\end{array}$

\begin{tabular}{ll}
\hline Participants & Number randomised: 40 patients \\
Age: mean 63.5 (60 to 70 ) years \\
Inclusion criteria: not reported \\
Exclusion criteria: high refractive defects ( $>4.0$ dioptres); other ocular pathologies; diabetes mellitus; \\
intraoperative or postoperative complications \\
Country: Italy
\end{tabular}

\begin{tabular}{|c|c|c|}
\hline Interventions & \multicolumn{2}{|c|}{$\begin{array}{l}\text { Phaco versus ECCE } \\
\text { Follow-up: Mean } 30 \text { days }\end{array}$} \\
\hline Outcomes & \multicolumn{2}{|c|}{$\begin{array}{l}\text { Specular Microscopy - EC density, CV; pachymetry; anterior segment fluorophotometry - EC pump func- } \\
\text { tion \& permeability coefficient } \\
\text { VA }\end{array}$} \\
\hline Notes & \multicolumn{2}{|l|}{1 surgeon } \\
\hline \multicolumn{3}{|l|}{ Risk of bias } \\
\hline Bias & Authors' judgement & Support for judgement \\
\hline Allocation concealment? & Unclear risk & B - Unclear \\
\hline
\end{tabular}


Rizal 2003

\begin{tabular}{ll}
\hline Methods & $\begin{array}{l}\text { Randomised controlled trial } \\
\text { Masking of outcome assessment: patient - yes; assessor - no }\end{array}$ \\
\hline Participants & $\begin{array}{l}\text { Number randomised: } 60 \text { patients } \\
\text { Age: Mean 64.8 (45 to 94) years } \\
\text { Inclusion criteria: age > 40; BCVA 6/60 or better; first cataract surgery } \\
\text { maculopathy; poor pupil dilatation; vitreous haemorrhage; corneal opacity; mental or physical handi- } \\
\text { cap; major surgery; CVA with significant visual loss } \\
\text { Country: Malaysia }\end{array}$ \\
\hline Interventions & $\begin{array}{l}\text { Phaco versus ECCE } \\
\text { Follow-up: mean 2 months }\end{array}$ \\
\hline Outcomes & Costs - hospital (recurrent / capital) and patient \\
\hline Notes & Short follow-up ECCE still need removal of sutures and 2 more appointments \\
\hline Risk of bias & Authors' judgement Support for judgement \\
\hline Bias & Unclear risk $\quad$ B - Unclear \\
\hline Allocation concealment?
\end{tabular}

\section{SACMS}

\begin{tabular}{|c|c|}
\hline Methods & $\begin{array}{l}\text { Randomised controlled trial } \\
\text { (Multicentre) } \\
\text { Masking of outcome assessment: not reported. Obvious difference of one treatment group wearing } \\
\text { aphakic glasses }\end{array}$ \\
\hline Participants & $\begin{array}{l}\text { Number randomised: } 1,237 \text { patients } \\
\text { Age: } 40 \text { to } 75 \text { years (mean } 61 \text { years) } \\
\text { Inclusion criteria: age } 40 \text { to } 75 \text {; VA } 6 / 60 \text { or less, but a minimum of PL in } 3 \text { quadrants better eye; cataract } \\
\text { grade } 2 \mathrm{~B} \text { and } 3 \\
\text { Exclusion criteria: known or suspected glaucoma; IOP > } 26 \mathrm{~mm} \mathrm{Hg} \text {; acute or chronic corneal disease; } \\
\text { shallow anterior chamber; anterior synechiae; congenital, complicated or traumatic cataract; non- } \\
\text { lenticular axial high myopia; one eye, aphakia, diabetic retinopathy; disease likely to cause death in } 3 \\
\text { years } \\
\text { Countries: western Nepal; Chittagong, Bangladesh; Hyderabad, India }\end{array}$ \\
\hline Interventions & $\begin{array}{l}\text { ICCE/AG versus ICCE/ACIOL } \\
\text { Follow-up: } 2 \text { years }\end{array}$ \\
\hline Outcomes & $\begin{array}{l}\text { VA; causes of severe visual impairment; corneal endothelial cell loss (corneal endothelial cells were } \\
\text { photographed using a non-contact specular microscope, images analysed using a semi-automated } \\
\text { technique) }\end{array}$ \\
\hline Notes & ACIOL: single-piece four-point fixation CILCO Kelman Multiflex III lens (Alcon) \\
\hline \multicolumn{2}{|l|}{ Risk of bias } \\
\hline Bias & Support for judgement \\
\hline
\end{tabular}


SACMS (Continued)
Allocation concealment?
Low risk
A - Adequate

Vogel 1993

$\begin{array}{ll}\text { Methods } & \text { Randomised controlled trial } \\ \text { Masking of outcome assessment: not reported. Obviously unable to mask AC IOL and PC IOL from as- } \\ \text { sessors }\end{array}$
sessors

\begin{tabular}{ll}
\hline Participants & $\begin{array}{l}\text { Number randomised: } 360 \text { patients } \\
\text { Age: } 60 \text { to } 80 \text { years (mean } 73 \text { years) } \\
\text { Inclusion criteria: age } 60 \text { to } 80 \\
\text { Exclusion criterial: no other ocular disease compromising vision } \\
\text { Country: Germany }\end{array}$ \\
\hline Interventions & ICCE/ACIOL versus ECCE/PCIOL \\
& Follow-up: 2 years \\
\hline Outcomes & VA; Complications \\
\hline Notes & ACIOL: Choyce Mark IV \\
\hline PCIOL: Ganz PMMA \\
\hline Bias of bias & Authors' judgement Support for judgement \\
\hline Allocation concealment? & Unclear risk $\quad$ B - Unclear \\
\hline
\end{tabular}

\section{Waddell 2004}

\begin{tabular}{ll}
\hline Methods & $\begin{array}{l}\text { Randomised controlled trial. Paired Study } \\
\text { Masking of outcome assessment: patient - yes. Not told the type of IOL implanted in each eye; assessor } \\
\text { - no. Type of IOL was obvious from examination of the eye }\end{array}$ \\
\hline Participants & Number randomised: 114 patients \\
& $\begin{array}{l}\text { Age: } 50 \text { to } 80 \text { years (mean } 64 \text { years) } \\
\text { Inclusion criteria: age = 50 years; bilateral cataract; VA 6/60 or worse in better eye } \\
\text { Exclusion criteria: VA worse than PL; significant keratopathy; glaucoma; ocular pathology; home too } \\
\text { inaccessible to visit } \\
\text { Country: Rural north and East Uganda }\end{array}$ \\
\hline Interventions & $\begin{array}{l}\text { ECCE \& PCIOL versus ICCE \& ACIOL } \\
\text { Follow-up: } 1 \text { year }\end{array}$ \\
\hline Outcomes & VA; complications; secondary procedures; refractive corrections \\
\hline Notes & $\begin{array}{l}1 \text { surgeon } \\
\text { ACIOL } 4 \text { feet mulitflex Aurolab, India } \\
\text { PCIOL Aurolab standard lens power }\end{array}$
\end{tabular}

\section{Risk of bias}


Waddell 2004 (Continued)

\begin{tabular}{lll} 
Bias & Authors' judgement & Support for judgement \\
\hline Allocation concealment? & Low risk & A - Adequate \\
\hline
\end{tabular}

AG - aphakic glasses

ACIOL - anterior chamber intraocular lens

CSME - clinical significant macular oedema

ECCE - extracapsular extraction

ICCE - intracapsular extraction

$\mathrm{IOL}$ - intraocular lens

$\mathrm{PCIOL}$ - posterior chamber intraocular lens

VA - visual acuity

Characteristics of excluded studies [ordered by study ID]

\begin{tabular}{ll}
\hline Study & Reason for exclusion \\
\hline Alpar 1984 & $\begin{array}{l}\text { This was a small study in people with diabetes comparing intracapsular with extracapsular cataract } \\
\text { extraction with intraocular lens implantation. Several of the lenses they used are now no longer } \\
\text { used. In addition, the trial was of poor quality and did not present the outcomes of interest to our } \\
\text { review, such as visual acuity. }\end{array}$ \\
\hline
\end{tabular}

Bomer 1995

This was a study comparing the effect on intraocular pressure following phacoemulsification through scleral tunnel; phacoemulsification and corneal incision and extracapsular extraction. We excluded this study since IOP was not one of the outcome measures for this paper.

Bourne 2003

This was a study looking at outcomes of cataract surgery in Bangladesh. This was not a randomised control trial.

De Laage 1988

This study compared intracapsular extraction with an anterior

chamber lens in one eye compared with extracapsular extraction and posterior chamber lens in the other. The allocation was not random, no concealment was mentioned and follow-up was only six months.

\section{Ford 2005}

This study compared the effect of different surgical techniques on postoperative intra-ocular pressure. It was not randomised and IOP is not an outcome measure for this paper.

\section{Hsu 2005}

This study compared phacoemulsificaction or extracapsular cataract extraction followed by pars plana vitrectomy and $\mathrm{PCIOL}$. Allocation concealment was not clear from the paper or whether randomisation was performed

\begin{tabular}{ll}
\hline Jurgens 1997 & $\begin{array}{l}\text { This study compared different types of viscoelastics. The surgical technique used was not ran- } \\
\text { domised. }\end{array}$
\end{tabular}

Leen 1993 This study compared different incision sizes as opposed to different surgical techniques hence was excluded from this review.

\begin{tabular}{ll}
\hline Loo 2004 & $\begin{array}{l}\text { This study compared the cost-effectiveness and cost efficiency of phacoemulsifiaction and extra- } \\
\text { capsular extraction. This was not a randomized control trial. }\end{array}$ \\
\hline Noske 1988 & $\begin{array}{l}\text { This study compared the effect of acetazolamide on IOP following phacoemulsification or extra- } \\
\text { capsular extraction. IOP is not an outcome measure for this review. }\end{array}$ \\
\hline Quentin 1993 & $\begin{array}{l}\text { This study compared intracapsular cataract extraction with anterior chamber intraocular lens } \\
\text { (Choyce Mark IX) with extracapsular cataract extraction. Follow-up data included only six months } \\
\text { after surgery. }\end{array}$
\end{tabular}




\begin{tabular}{ll}
\hline Study & Reason for exclusion \\
\hline Ruellan 1994 & $\begin{array}{l}\text { This study compared phacoemulsification and extracapsular extraction. There was no informa- } \\
\text { tion regarding allocation concealment or randomisation in the paper hence there was a high risk of } \\
\text { bias. }\end{array}$ \\
\hline
\end{tabular}

DATA AND ANALYSES

Comparison 1. PHACOEMULSIFICATION WITH PCIOL VERSUS EXTRACAPSULAR EXTRACTION WITH PCIOL

\begin{tabular}{lllll}
\hline Outcome or subgroup title & $\begin{array}{l}\text { No. of } \\
\text { studies }\end{array}$ & $\begin{array}{l}\text { No. of } \\
\text { partici- } \\
\text { pants }\end{array}$ & Statistical method & Effect size \\
\hline 1 Clinical complications & 2 & 571 & Odds Ratio (M-H, Fixed, 95\% Cl) & $0.25[0.07,0.91]$ \\
\hline 1.1 Macular oedema & 2 & 571 & Odds Ratio (M-H, Fixed, 95\% Cl) & $0.25[0.07,0.91]$ \\
\hline 2 Complications during surgery & 6 & & Risk Ratio (M-H, Fixed, 95\% Cl) & Totals not selected \\
\hline 2.1 Iris Prolapse & 6 & & Risk Ratio (M-H, Fixed, 95\% Cl) & $0.0[0.0,0.0]$ \\
\hline 2.2 PC Tear +/- Vitreous Loss & 6 & Risk Ratio (M-H, Fixed, 95\% Cl) & $0.0[0.0,0.0]$
\end{tabular}

Analysis 1.1. Comparison 1 PHACOEMULSIFICATION WITH PCIOL VERSUS EXTRACAPSULAR EXTRACTION WITH PCIOL, Outcome 1 Clinical complications.

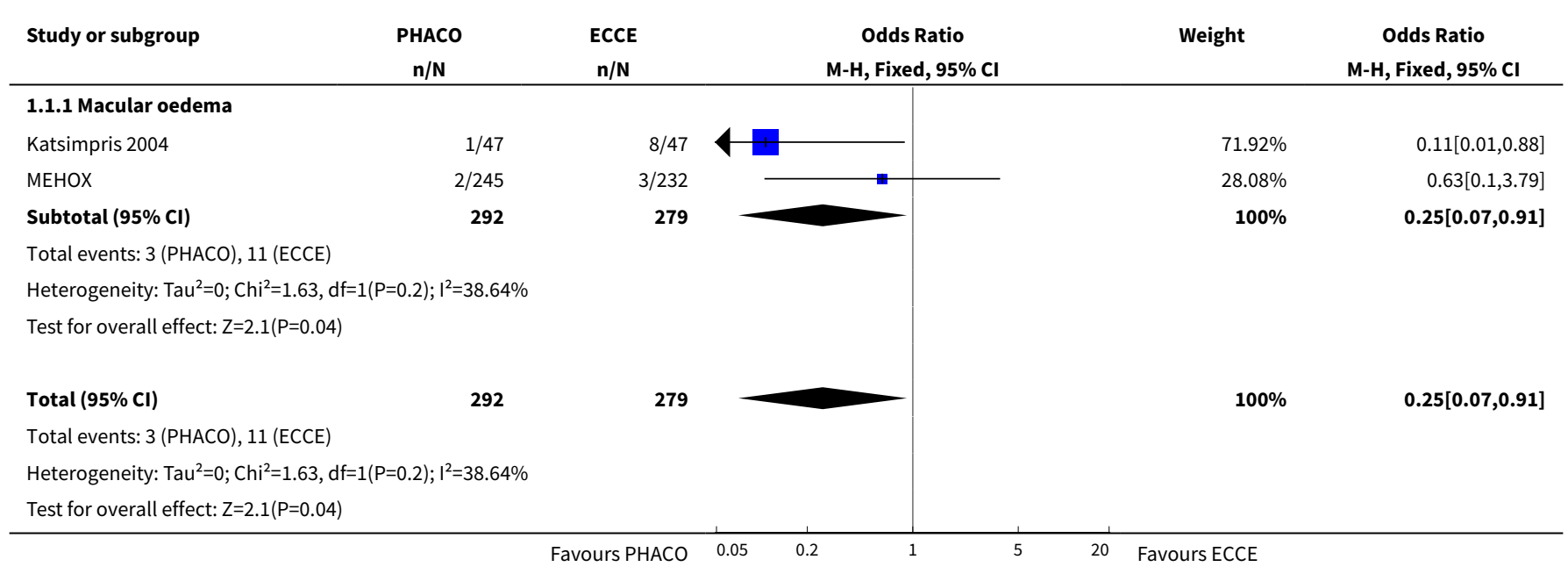


Analysis 1.2. Comparison 1 PHACOEMULSIFICATION WITH PCIOL VERSUS EXTRACAPSULAR EXTRACTION WITH PCIOL, Outcome 2 Complications during surgery.

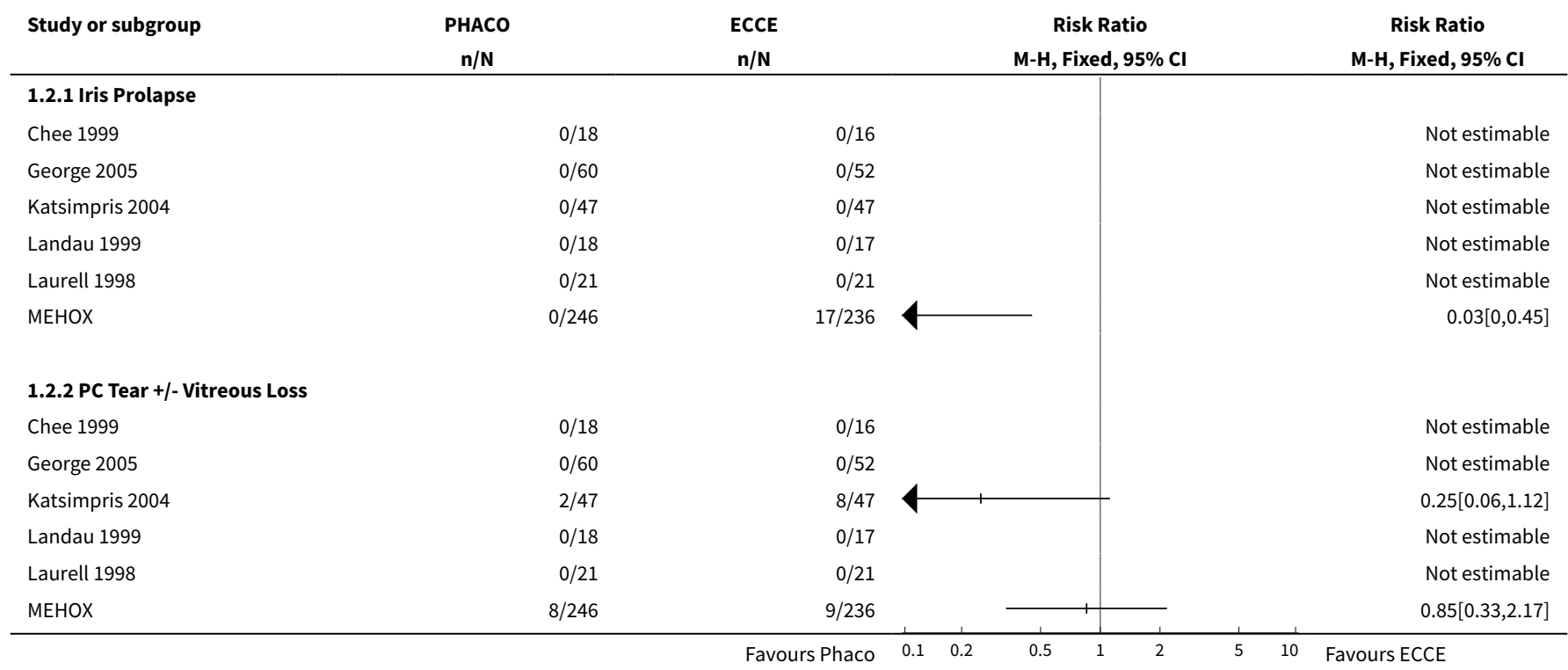

Comparison 2. PHACOEMULSIFICATION WITH PCIOL VERSUS MANUAL SMALL INCISION EXTRACTION WITH PCIOL

\begin{tabular}{lllll}
\hline Outcome or subgroup title & $\begin{array}{l}\text { No. of } \\
\text { studies }\end{array}$ & $\begin{array}{l}\text { No. of } \\
\text { partici- } \\
\text { pants }\end{array}$ & Statistical method & Effect size \\
\hline $\begin{array}{l}\text { 1 Best corrected vision worse than 6/60, } \\
\text { 4-12 weeks after surgery }\end{array}$ & 2 & 485 & Risk Ratio (M-H, Fixed, 95\% Cl) & $0.95[0.14,6.45]$ \\
\hline $\begin{array}{l}\text { 2 Functional vision worse than 6/18, 4-12 } \\
\text { weeks after surgery }\end{array}$ & 2 & 485 & Risk Ratio (M-H, Fixed, 95\% Cl) & $0.76[0.19,3.02]$ \\
\hline 3 Complications during surgery & 2 & & Odds Ratio (M-H, Fixed, 95\% Cl) & Totals not selected \\
\hline 3.1 PC Tear +/- Vit loss & 2 & Odds Ratio (M-H, Fixed, 95\% Cl) & $0.0[0.0,0.0]$ \\
\hline
\end{tabular}

Analysis 2.1. Comparison 2 PHACOEMULSIFICATION WITH PCIOL VERSUS MANUAL SMALL INCISION EXTRACTION WITH PCIOL, Outcome 1 Best corrected vision worse than 6/60, 4-12 weeks after surgery.

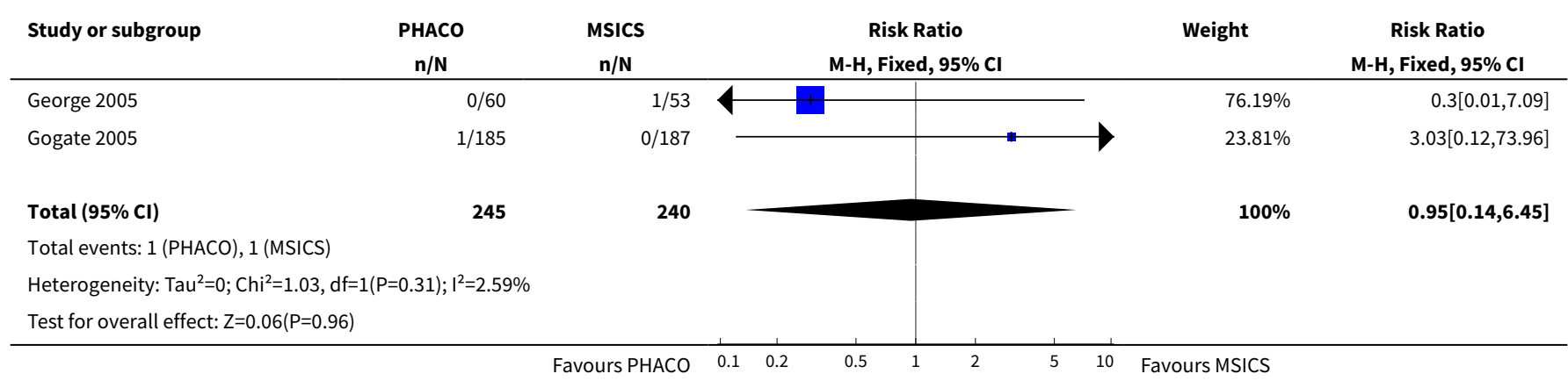


Analysis 2.2. Comparison 2 PHACOEMULSIFICATION WITH PCIOL VERSUS MANUAL SMALL INCISION EXTRACTION WITH PCIOL, Outcome 2 Functional vision worse than 6/18, 4-12 weeks after surgery.

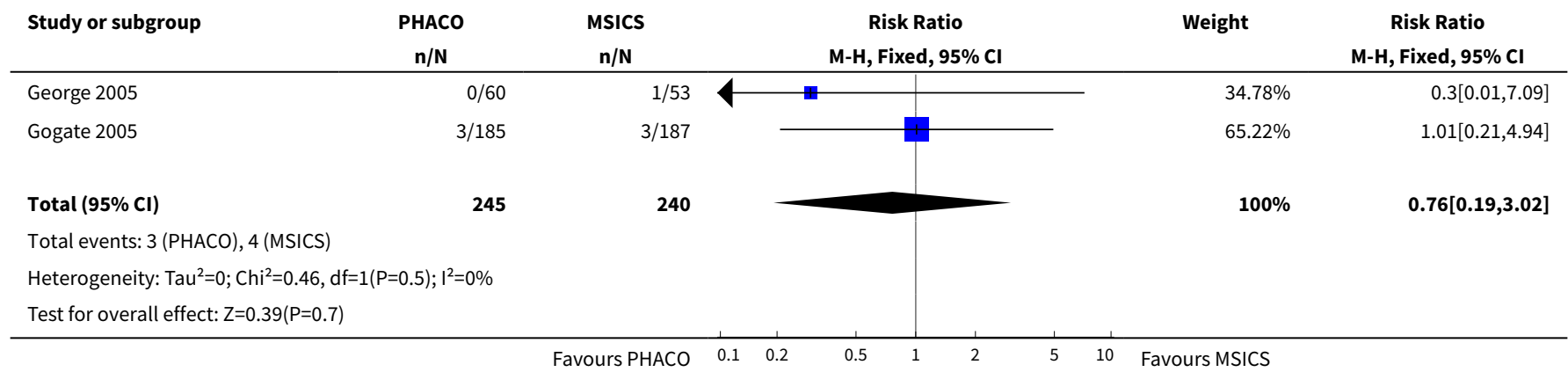

Analysis 2.3. Comparison 2 PHACOEMULSIFICATION WITH PCIOL VERSUS MANUAL SMALL INCISION EXTRACTION WITH PCIOL, Outcome 3 Complications during surgery.

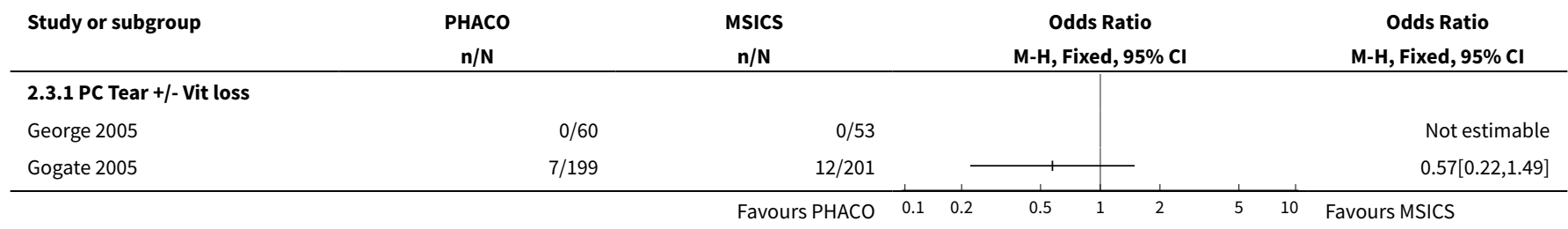

Comparison 3. EXTRACAPSULAR EXTRACTION WITH PCIOL VERSUS MANUAL SMALL INCISION EXTRACTION WITH PCIOL

\begin{tabular}{lllll}
\hline Outcome or subgroup title & $\begin{array}{l}\text { No. of } \\
\text { studies }\end{array}$ & $\begin{array}{l}\text { No. of } \\
\text { partici- } \\
\text { pants }\end{array}$ & Statistical method & Effect size \\
\hline $\begin{array}{l}\text { 1 Best corrected vision worse than 6/60, } \\
\text { 4-12 weeks after surgery }\end{array}$ & 2 & 811 & Risk Ratio (M-H, Fixed, 95\% Cl) & $0.81[0.26,2.49]$ \\
\hline $\begin{array}{l}\text { 2 Functional vision worse than 6/18, 4-12 } \\
\text { weeks after surgery }\end{array}$ & 2 & 811 & Risk Ratio (M-H, Fixed, 95\% Cl) & $1.41[0.94,2.09]$ \\
\hline 3 Complications during surgery & 2 & & Odds Ratio (M-H, Fixed, 95\% Cl) & Totals not selected \\
\hline 3.1 PC Tear +/- Vit loss & 2 & & Odds Ratio (M-H, Fixed, 95\% Cl) & $0.0[0.0,0.0]$ \\
\hline
\end{tabular}


Analysis 3.1. Comparison 3 EXTRACAPSULAR EXTRACTION WITH PCIOL VERSUS MANUAL SMALL INCISION EXTRACTION WITH PCIOL, Outcome 1 Best corrected vision worse than 6/60, 4-12 weeks after surgery.

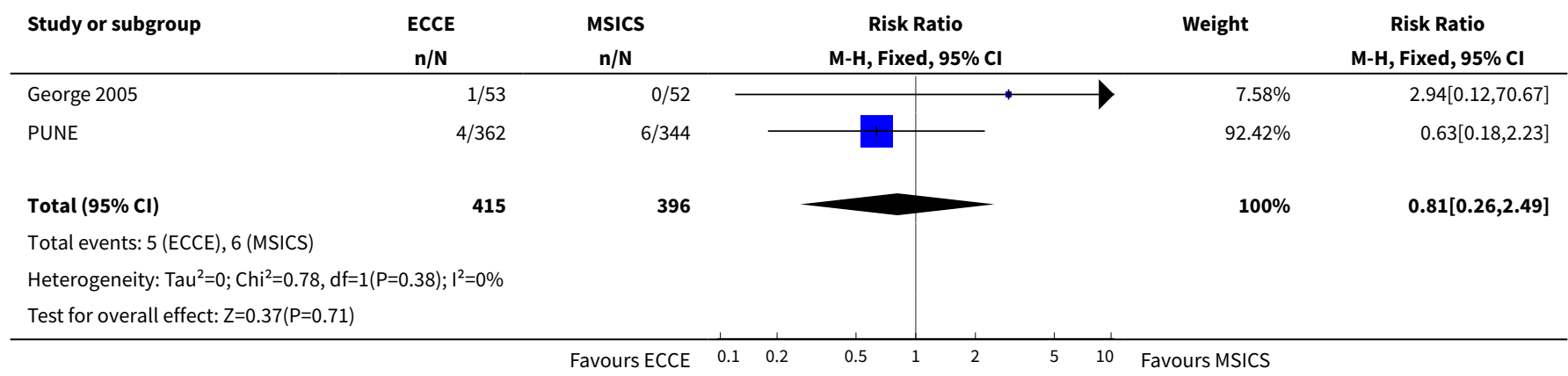

Analysis 3.2. Comparison 3 EXTRACAPSULAR EXTRACTION WITH PCIOL VERSUS MANUAL SMALL INCISION EXTRACTION WITH PCIOL, Outcome 2 Functional vision worse than 6/18, 4-12 weeks after surgery.

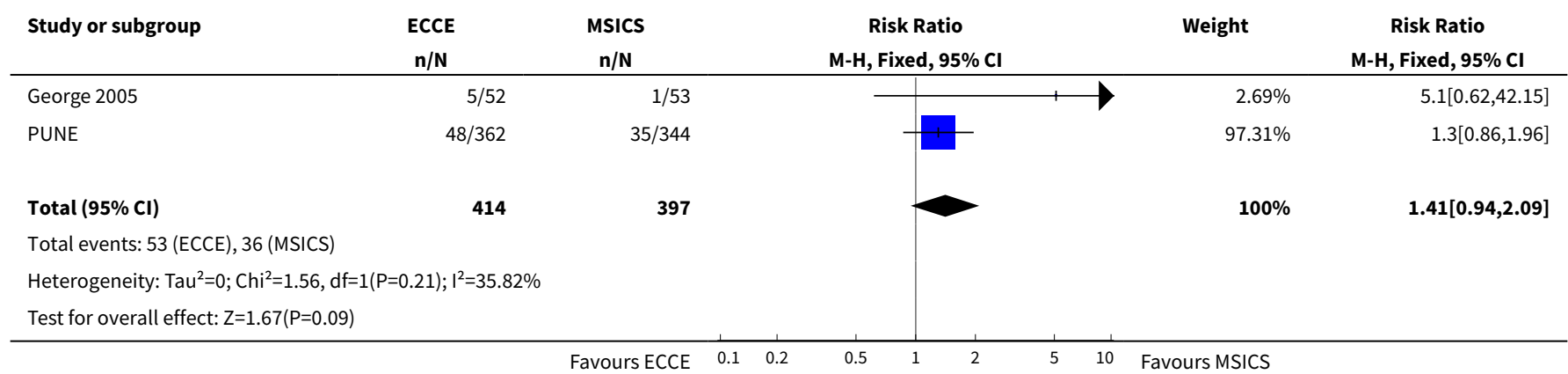

Analysis 3.3. Comparison 3 EXTRACAPSULAR EXTRACTION WITH PCIOL VERSUS MANUAL SMALL INCISION EXTRACTION WITH PCIOL, Outcome 3 Complications during surgery.

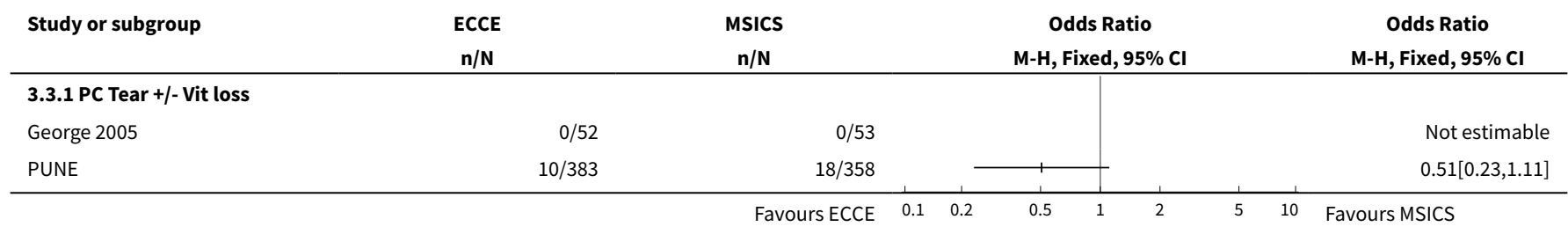

\section{Comparison 4. INTRACAPSULAR EXTRACTION WITH ACIOL VERSUS INTRACAPSULAR EXTRACTION WITH GLASSES}

\begin{tabular}{llll}
\hline Outcome or subgroup title & $\begin{array}{l}\text { No. of } \\
\text { studies }\end{array}$ & $\begin{array}{l}\text { No. of } \\
\text { partici- } \\
\text { pants }\end{array}$ & Statistical method \\
\hline $\begin{array}{l}1 \text { Best-corrected vision worse than } \\
6 / 60, \text { one year after surgery }\end{array}$ & 2 & 2866 & Risk Ratio (M-H, Fixed, $95 \% \mathrm{Cl})$ \\
\hline
\end{tabular}




\begin{tabular}{lllll}
\hline Outcome or subgroup title & $\begin{array}{l}\text { No. of } \\
\text { studies }\end{array}$ & $\begin{array}{l}\text { No. of } \\
\text { partici- } \\
\text { pants }\end{array}$ & Statistical method & Effect size \\
\hline $\begin{array}{l}\text { 2 Functional vision worse than } \\
6 / 18, \text { one year after surgery }\end{array}$ & 2 & 2867 & Risk Ratio (M-H, Fixed, 95\% Cl) & $1.25[1.16,1.35]$ \\
\hline 3 Clinical complications & 2 & Risk Ratio (M-H, Fixed, 95\% Cl) & Totals not selected \\
\hline 3.1 Retinal detachment & 2 & Risk Ratio (M-H, Fixed, 95\% Cl) & $0.0[0.0,0.0]$ \\
\hline 3.2 Macular oedema & 2 & Risk Ratio (M-H, Fixed, 95\% Cl) & $0.0[0.0,0.0]$ \\
\hline 3.3 Corneal decompensation & 2 & Risk Ratio (M-H, Fixed, 95\% Cl) & $0.0[0.0,0.0]$
\end{tabular}

Analysis 4.1. Comparison 4 INTRACAPSULAR EXTRACTION WITH ACIOL VERSUS INTRACAPSULAR EXTRACTION WITH GLASSES, Outcome 1 Best-corrected vision worse than $6 / 60$, one year after surgery.

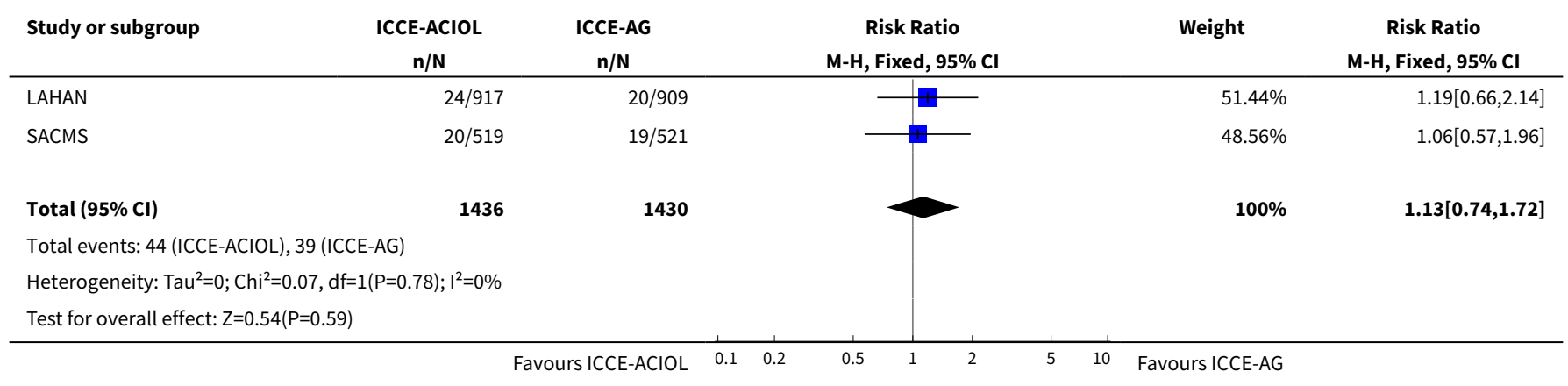

Analysis 4.2. Comparison 4 INTRACAPSULAR EXTRACTION WITH ACIOL VERSUS INTRACAPSULAR EXTRACTION WITH GLASSES, Outcome 2 Functional vision worse than $6 / 18$, one year after surgery.

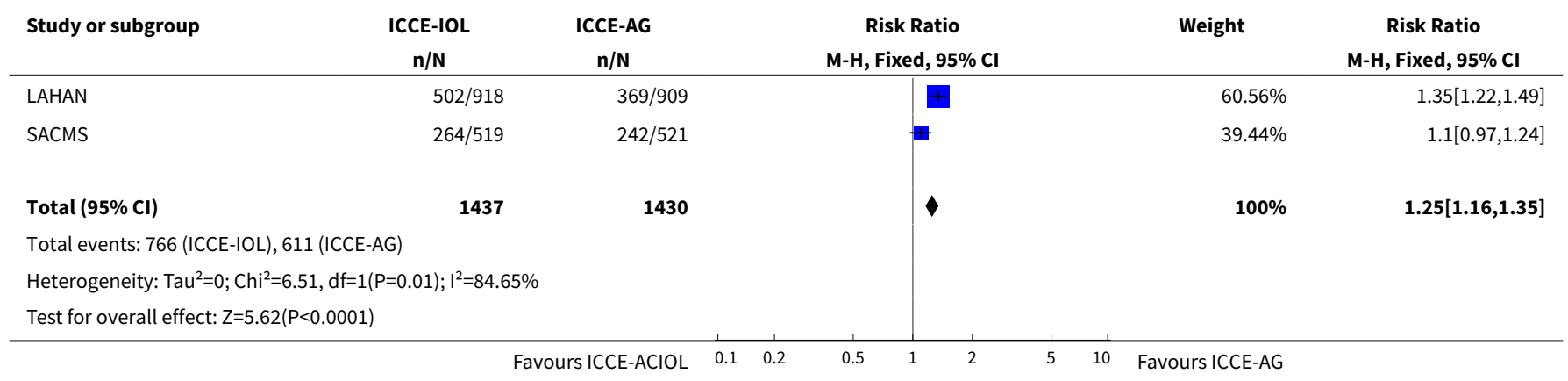


Analysis 4.3. Comparison 4 INTRACAPSULAR EXTRACTION WITH ACIOL VERSUS INTRACAPSULAR EXTRACTION WITH GLASSES, Outcome 3 Clinical complications.

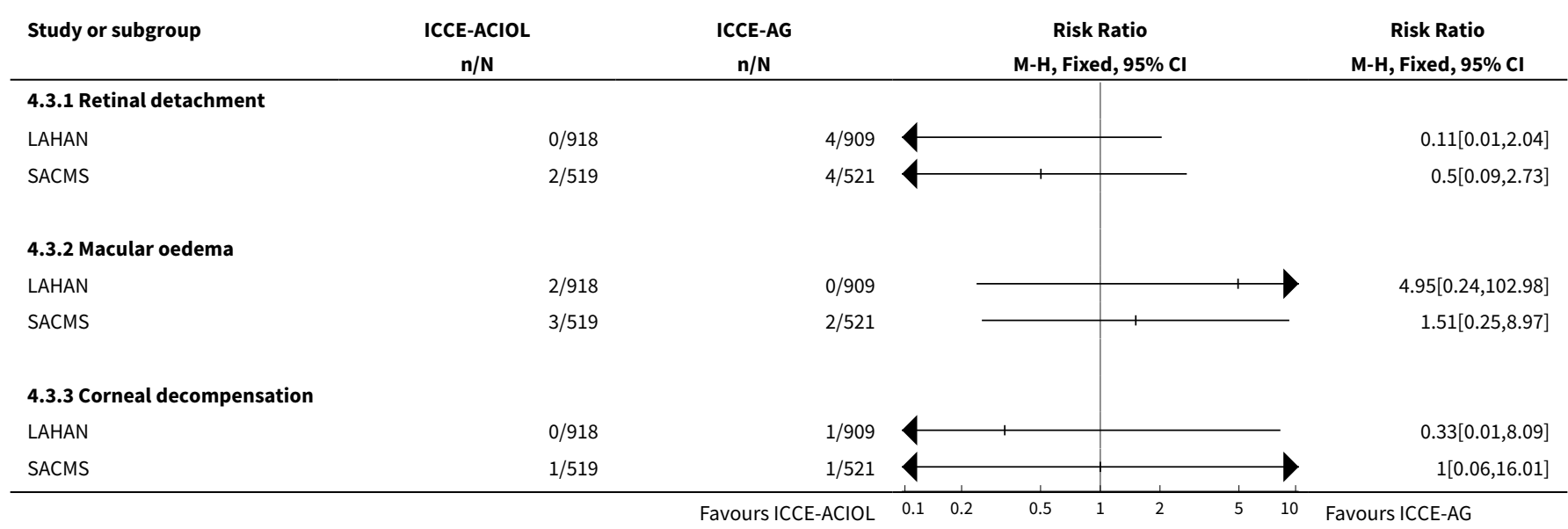

\section{ADDITIONAL TABLES}

Table 1. Heterogeneity of visual outcome data for PHACO with IOL versus ECCE with PCIOL

\begin{tabular}{|c|c|c|c|}
\hline Study & Post op follow up & BCVA/BSCVA data & UCVA data \\
\hline MEHOX & $\begin{array}{l}3 \text { weeks, } 6 \text { weeks, } 3 \text { months, } 6 \text { months, } 12 \\
\text { months }\end{array}$ & $\begin{array}{l}\text { BSCVA of } 6 / 9 \text { or better; BSCVA of } \\
6 / 12 \text { or better ( } 12 \text { months only) }\end{array}$ & UCVA of $6 / 9$ or better \\
\hline Dowler 2000 & $\begin{array}{l}\text { only } 1 \text { year data presented (although VA } \\
\text { also recorded at } 6 \text { months) }\end{array}$ & Median BCVA & UCVA not recorded \\
\hline $\begin{array}{l}\text { Katsimpris } \\
2004\end{array}$ & 14 months & Mean BCVA & UCVA not recorded \\
\hline Chee 1999 & $\begin{array}{l}\text { VA was only reported at } 2 \text { months (al- } \\
\text { though maximum follow up time was } 3 \\
\text { months) }\end{array}$ & BCVA of $6 / 12$ or better & UCVA of $6 / 12$ or better \\
\hline George 2005 & 6 weeks & BCVA of $6 / 12$ or better & UCVA not recorded \\
\hline Laurell 1998 & 1 day, 3 days, 3 months & $\begin{array}{l}\text { BCVA of } 6 / 9 \text { or better ( } 1 \text { day only); } \\
\text { BCVA of } 6 / 6 \text { ( } 3 \text { days and } 3 \text { months) }\end{array}$ & $\begin{array}{l}\text { UCVA of } 20 / 100 \text { or less ( } 1 \text { day } \\
\text { and } 3 \text { days only) }\end{array}$ \\
\hline $\begin{array}{l}\text { Ravalico } \\
1997\end{array}$ & 7 days, 30 days & Mean BCVA & $\begin{array}{l}\text { UCVA is not presented (although } \\
\text { was performed) }\end{array}$ \\
\hline
\end{tabular}

Table 2. Postoperative BCVA results for PHACO with PCIOL versus ECCE with PCIOL studies

\begin{tabular}{lll}
\hline Study & Early visual outcome & Late visual outcome \\
\hline MEHOX & BCVA 6/9 or better at 6 weeks (12 weeks) - PHACO: $90 \%$ (93\%); & BCVA 6/9 or better at 12 months - PHACO: \\
& ECCE: $78 \%(80 \%)$ & ECCE: $86 \%$ \\
\hline
\end{tabular}


Table 2. Postoperative BCVA results for PHACO with PCIOL versus ECCE with PCIOL studies (Continued)

\begin{tabular}{|c|c|c|}
\hline Dowler 2000 & Not recorded & $\begin{array}{l}\text { BCVA 6/12 or better at } 12 \text { months - PHACO: } \\
96 \% \text {; ECCE: } 83 \%\end{array}$ \\
\hline Katsimpris 2004 & Not recorded & $\begin{array}{l}\text { Mean BCVA decimal at } 14 \text { months - PHACO: } \\
0.5 \text {; ECCE: } 0.3\end{array}$ \\
\hline Chee 1999 & BCVA $6 / 12$ or better at 8 weeks - PHACO: $94 \%$; ECCE: $94 \%$ & Not recorded \\
\hline George 2005 & BCVA $6 / 12$ or better at 6 weeks - PHACO: $100 \%$; ECCE: $90 \%$ & Not recorded \\
\hline Laurell 1998 & BCVA $6 / 6$ or better at 12 weeks - PHACO: $76 \%$; ECCE: $45 \%$ & Not recorded \\
\hline Ravalico 1997 & Mean BCVA at 4 weeks - PHACO: $0.95 \pm 0.11$; ECCE: $0.92 \pm 0.10$ & Not recorded \\
\hline
\end{tabular}

\section{APPENDICES}

\section{Appendix 1. CENTRAL search strategy for Issue 3, 2006 and NRR search strategy for Issue 3, 2005}

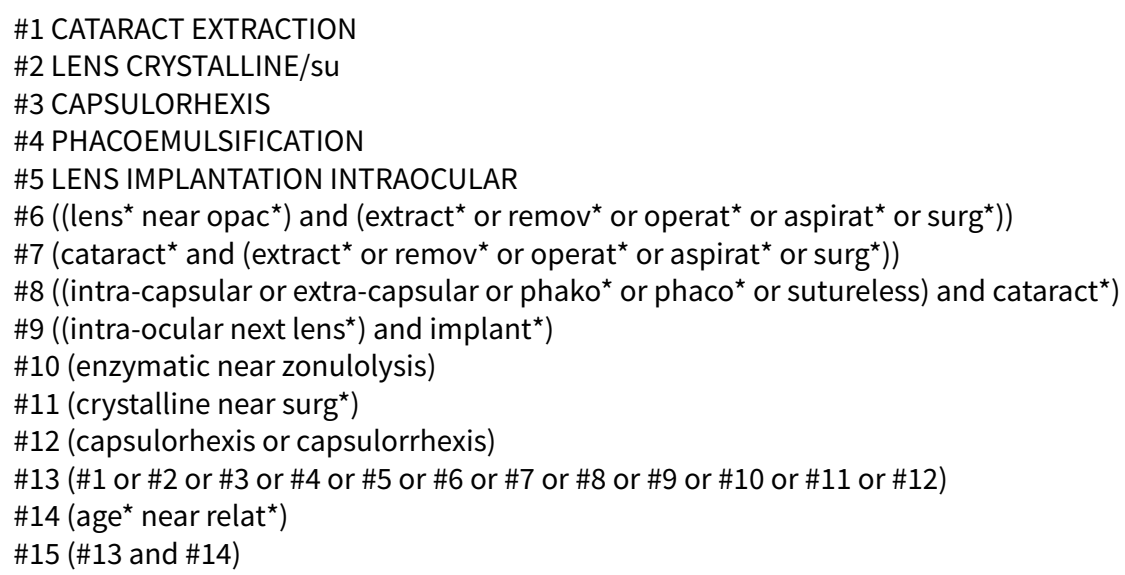

\section{Appendix 2. MEDLINE search strategy used up to July 2006}

\#1 explode "Cataract-Extraction" / all SUBHEADINGS in MIME,MJME

\#2 explode "Lens-Crystalline" / surgery in MIME,MJME

\#3 explode "Capsulorhexis-" / all SUBHEADINGS in MIME,MJME

\#4 explode "Phacoemulsification-" / all SUBHEADINGS in MIME,MJME

\#5 explode "Lens-Implantation-Intraocular" / all SUBHEADINGS in MIME,MJME

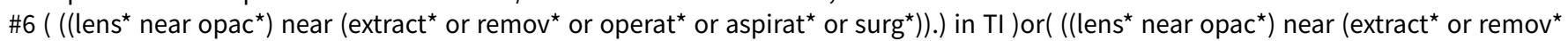
or operat ${ }^{\star}$ or aspirat* or surg* $\left.\left.^{\star}\right)\right)$.) in AB )

\#7 ( (cataract* near (extract* or remov* or operat* or aspirat* or surg*)).) in $\mathrm{TI}$ )or( (extract* or remov* or operat* or aspirat* or surg*)).))) in $\mathrm{AB})$

\#8 ( (intra?capsular or extra?capsular or pha?o* or sutureless) near ((cataract*) in TI )or( (intra?capsular or extra?capsular or pha?o* or sutureless) near ((cataract*) in AB)

\#9 ( (intra?ocular next lens $\left.{ }^{\star}\right)$ near ((implant $\left.{ }^{\star}\right)$ in TI) )or( (intra?ocular next lens $\left.{ }^{\star}\right)$ near ((implant $\left.{ }^{\star}\right)$ in AB) )

$\# 10$ ( (enzymatic zonulolysis) in TI )or( (enzymatic zonulolysis) in AB )

$\# 11$ ( (crystalline near surg $\left.{ }^{\star}\right)$ in $\mathrm{TI}$ ) or( (crystalline near surg $\left.{ }^{\star}\right)$ in $\left.A B\right)$

$\# 12$ ( (capsulor?hexis) in TI )or( (capsulor?hexis) in AB)

$\# 13 \# 1$ or \#2 or \#3 or \#4 or \#5 or \#6 or \#7 or \#8 or \#9 or \#10 or \#11 or \#12 or \#13

$\# 14$ age $^{\star}$ near relat*

\#15 \#13 AND \#14

To identify randomised controlled trials, we combined this search with the Cochrane Highly Sensitive Search Strategy phases one and two as contained in the Cochrane Handbook for Systematic Reviews of interventions (Higgins 2005a). 


\section{Appendix 3. EMBASE search strategy used up to July 2006}

\#1 exp Cataract Extraction/

\#2 exp lens/

\#3 su.fs.

$\# 42$ and 3

\#5 exp CAPSULORHEXIS/

\#6 exp PHACOEMULSIFICATION/

\#7 exp Lens Implantation/

\#8 1 or 4 or 5 or 6 or 7

\#9 (lens\$ adj3 opac\$ adj5 (extract\$ or remov\$ or operat\$ or aspirat\$ or surg\$)).ab,ti.

$\# 10$ (cataract\$ adj3 (extract\$ or remov\$ or operat\$ or aspirat\$ or surg\$)).ab,ti.

\#11 ((intracapsular or intra-capsular or extracapsular or extra-capsular or phaco $\$$ or phako $\$$ or sutureless) adj5 cataract\$).ab,ti.

\#12 ((intraocular or intra-ocular) adj3 lens\$ adj3 implant\$).ab,ti.

\#13 enzymatic zonulolysis.ab,ti.

\#14 exp zonulolysis/

\#15 (crystalline adj3 surg\$).ab,ti.

\#16 (capsulorhexis or capsulorrhexis).ab,ti.

\#17 catarectomy.ab,ti.

\#18 9 or 10 or 11 or 12 or 13 or 14 or 15 or 16 or 17

$\# 198$ or 18

\#20 (2001\$ or $2002 \$$ or $2003 \$$ or $2004 \$$ or $2005 \$$ ).em.

\#21 19 and 20

\#22 elderly care.sh.

\#23 exp senescence/

\#24 Aged/

\#25 (old\$ adj3 age\$).ab,ti.

\#26 (age\$ adj3 related).ab,ti.

\#27 pensioner.sh.

\#28 (aged or elderly or pensioner\$ or (old adj3 age\$)).ab,ti.

\#29 21 and 28

\#30 22 or 23 or 24 or 25 or 26 or 27 or 28 or 29

\#31 21 and 30

To identify randomised controlled trials, this search was combined with the following search:

\#1 Randomized Controlled Trial/

\#2 exp Randomization/

\#3 Double Blind Procedure/

\#4 Single Blind Procedure/

\#5 random $\$$.ab,ti.

\#6 \#1 or \#2 or \#3 or \#4 or \#5

$\# 7$ (animal or animal experiment).sh.

\#8 human.sh.

$\# 9$ \#7 and \#8

$\# 10 \# 7$ not \#9

$\# 11$ \#6 not \#10

\#12 Clinical Trial/

\#13 (clin\$ adj3 trial\$).ab,ti.

\#14 ((singl\$ or doubl\$ or trebl\$ or tripl\$) adj3 (blind\$ or mask\$)).ab,ti.

\#15 exp PLACEBO/

\#16 placebo\$.ab,ti.

\#17 random\$.ab,ti.

\#18 experimental design/

\#19 Crossover Procedure/

\#20 exp Control Group/

\#21 exp LATIN SQUARE DESIGN/

$\# 22 \# 12$ or \#13 or \#14 or \#15 or \#16 or \#17 or \#18 or \#19 or \#20 or \#21

\#23 \#22 not \#10

\#24 \#23 not \#11

\#25 exp Comparative Study/

\#26 exp Evaluation/

\#27 exp Prospective Study/ 
\#28 (control\$ or prospectiv\$ or volunteer\$).ab,ti.

\#29 \#25 or \#26 or \#27 or \#28

\#30 \#29 not \#10

\#31 \#30 not (\#11 or \#23)

\#32 \#11 or \#24 or \#31

WHAT'S NEW

\begin{tabular}{lll}
\hline Date & Event & Description \\
\hline 3 November 2008 & Amended & Converted to new review format.
\end{tabular}

\section{HIST O R Y}

Protocol first published: Issue 4, 1998

Review first published: Issue 2, 2002

\begin{tabular}{lll}
\hline Date & Event & Description \\
\hline 23 August 2006 & $\begin{array}{l}\text { New citation required and conclusions } \\
\text { have changed }\end{array}$ & Substantive amendment \\
\hline
\end{tabular}

\section{CONTRIBUTIONS OF AUTHORS}

First issue of review

TS wrote the protocol, assessed search results and study quality, extracted and entered data and wrote the text of the review.

JE assessed search results and study quality, extracted and entered data and edited the text of the review.

TR commented on the review.

AF commented on the review.

Update of review

YR assessed search results and study quality, extracted and entered data and edited the text of the review.

JM assessed search results and study quality, extracted and entered data and wrote and edited the text of the review.

\section{DECLARATIONS OF INTEREST}

Four of the co-authors (JE, AF, TR,TS) have been involved in the funding, design, execution and analysis of three of the trials included in this review (LAHAN; MIOLS; SACMS).

\section{INDEX TERMS}

\section{Medical Subject Headings (MeSH)}

Age Factors; Cataract Extraction [ ${ }^{*}$ methods]; Phacoemulsification; Randomized Controlled Trials as Topic

\section{MeSH check words}

Humans 